\title{
Adaptive geographical clines in the growth and defense of a native plant
}

\author{
Ellen C. Woods, ${ }^{1}$ Amy P. Hastings, ${ }^{1}$ Nash E. Turley,${ }^{2,5}$ Stephen B. Heard, ${ }^{3}$ and Anurag A. Agrawal ${ }^{1,4,6}$ \\ ${ }^{1}$ Department of Ecology and Evolutionary Biology, Cornell University, Corson Hall, Ithaca, New York 14853-2701 USA \\ ${ }^{2}$ Department of Plant Biology, Box 7612, North Carolina State University, Raleigh, North Carolina 27695-7612 USA \\ ${ }^{3}$ Department of Biology, University of New Brunswick, Fredericton, New Brunswick E3B 1R3 Canada \\ ${ }^{4}$ Department of Entomology, Cornell University, Comstock Hall, Ithaca, New York 14853 USA
}

\begin{abstract}
Broad-scale geographical gradients in the abiotic environment and interspecific interactions should select for clinal adaptation. How trait clines evolve has recently received increased attention because of anticipated climate change and the importance of rapid evolution in invasive species. This issue is particularly relevant for clines in growth and defense of plants, because both sets of traits are closely tied to fitness and because such sessile organisms experience strong local selection. Yet despite widespread recognition that growth and defense traits are intertwined, the general issue of their joint clinal evolution is not well resolved.

To address heritable clinal variation and adaptation of growth and defense traits of common milkweed (Asclepias syriaca), we planted seed from 22 populations encompassing the species' latitudinal range in common gardens near the range center (New York) and toward the range edges (New Brunswick and North Carolina). Populations were differentiated in 13 traits, and six traits showed genetically based latitudinal clines. Higher-latitude populations had earlier phenology, lower shoot biomass, more root buds and clonal growth, higher rootto-shoot ratio, and greater latex production. The cline in shoot biomass was consistent in all three locations. Selection on phenology was reversed in New Brunswick and North Carolina, with early genotypes favored in the north but not the south. We found no clines in foliar trichomes or toxic cardenolides. Annual precipitation of source populations explained variation in phenology, clonal growth, root-to-shoot ratio, and latex. Across four traits measured in New Brunswick and North Carolina, we found garden-by-latitude (and gardenby-precipitation) interactions, indicating plasticity in genetically based trait clines.

In the two gardens with substantial herbivory (New York and North Carolina), northern populations showed higher resistance to insects. Resistance to aphids was driven by trichomes and water content, while resistance to monarch caterpillars was driven by latex. However, surveys of natural populations indicated that leaf damage and insect diversity on milkweed are low at the geographical extremes (New Brunswick and North Carolina) and higher toward the range center. We speculate that milkweed plants evolved clines in growth traits in response to climate, and that this set the template for tolerance to herbivory, which subsequently shaped the evolution of defensive traits.
\end{abstract}

Key words: Asclepias syriaca; clinal adaptation; common milkweed; Danaus plexippus; latex; latitudinal gradients; monarch butterfly; phenology; plant-insect interactions; plant life-history strategy; precipitation; reciprocal transplant experiment.

\section{INTRODUCTION}

Discovering the patterns and processes of adaptation to ecological gradients has been of central importance in the development of population biology (Mayr 1956, Harper 1977, Lambers et al. 1998). In particular, deciphering the evolutionary ecology of trait clines aids in understanding how biotic and abiotic factors interact to shape organismal evolution over large geographic

Manuscript received 9 August 2011; revised 3 October 2011; accepted 28 October 2011. Corresponding Editor: C. Gratton.

${ }^{5}$ Present address: Department of Biology, University of Toronto Mississauga, 3359 Mississauga Road North, Mississauga, Ontario L5L 1C6 Canada

${ }^{6}$ Corresponding Author. E-mail: agrawal@cornell.edu scales. When studies of conspecific individuals collected from multiple populations are conducted in common environments, a heritable basis to traits and their clinal variation can be inferred, with genetically based geographical clines thought to signify adaptation (Turesson 1930, Endler 1977, Hall et al. 2007, Stillwell et al. 2007). Common environment studies are critical because phenotypic plasticity in response to growing conditions can also generate clines, and such plasticity can obscure genetically based trait expression. Thus, reciprocal transplant experiments are the most rigorous way of demonstrating adaptive clines, as the genetic and environmental basis of trait expression can be tied to fitness components in matched and mismatched envi- 
ronments (Clausen et al. 1948, Chapin and Chapin 1981, Santamaría et al. 2003, Maron et al. 2004). Where reciprocal transplants are impractical, as with many animal species, measures of natural selection along the gradient can demonstrate the adaptive value of trait clines (Antoniazza et al. 2010, Stillwell 2010).

Studies of latitudinal clines in life-history strategy have recently accelerated because of their importance to two aspects of global change. First, rapid evolution has been recognized in invasive plant and animal species following introduction to new environments (Huey et al. 2000, Kolbe et al. 2004, Colautti et al. 2009). For example, Maron et al. (2004) showed that genetically based trait clines in native and invasive populations of St. John's wort (Hypericum perforatum) have converged, suggesting that performance traits are locally adapted. Parallel studies on native and invasive fruit flies have similarly shown rapid evolution of geographical clines (Huey et al. 2000). Second, anticipated global climate change has called attention to the potential for organisms to rapidly adapt to environmental change, but whether species can realize this potential will depend on various ecological factors and intrinsic genetic attributes (Spicer and Chapman 1990, Arft et al. 1999, Davis et al. 2005, Skelly et al. 2007, Colautti et al. 2010).

The study of geographical clines had been a particular focus for plant ecologists, because climate has very strong impacts on plant performance, and because sessile organisms are likely to experience strong local selection. Latitudinal gradients in climatic variables, including temperature, growing season length, and precipitation, have shaped intraspecific clines in plant traits, especially those related to life-history (Chapin et al. 1993). For example, high-latitude populations tend to evolve small seededness ( $\mathrm{Li}$ et al. 1998, Moles et al. 2007), earlier phenologies (Turesson 1930, Winn and Gross 1993, Montague et al. 2008), slower growth rates (Chapin and Chapin 1981, Li et al. 1998), and greater investment in clonal over sexual reproduction (Pilon et al. 2003). However, the role of such clines in the broader context of ecogeographic variation (e.g., interspecific interactions) is thus far little explored (Agrawal 2011).

A largely separate ecological literature has developed on biogeographic clines in species interactions. Although notions of latitudinal variation in diversity and interactions predate Darwin and Wallace (Helferich 2004), Dobzhansky (1950) solidified the hypothesis that the intensity of biotic interactions increases at lower latitudes, favoring the evolution of exaggerated values of traits that mediate these interactions. In a recent review spanning animal and plant systems, evidence for stronger per capita interactions at lower latitudes was found for predation and herbivory (Schemske et al. 2009). Coley and Barone (1996) more specifically summarized clinal variation in herbivory, hypothesizing that the warmer and less seasonal climates of tropical latitudes make higher levels of insect attack possible.
Most work in this area, on terrestrial plants and oceanic seaweeds, has been comparative across species and has contrasted temperate vs. tropical species (Bolser and Hay 1996, Coley and Barone 1996, Schemske et al. 2009). At an intraspecific level, recent work by Pennings and colleagues has shown that genetically based plant resistance traits are higher at lower latitudes for several temperate plant species, and this corresponds to greater levels of herbivory in natural populations and bioassays (Siska et al. 2002, Salgado and Pennings 2005, Pennings et al. 2009).

An alternative to latitudinal clines in herbivory is the possibility that distance (in any direction) away from the range center is associated with altered species interactions (Garcia et al. 2000, Alexander et al. 2007, Gaston 2009). The logic behind this prediction is that near the range center, high abundances of the focal species may result in altered interaction strengths compared to sparser populations away from the range center (Alexander et al. 2007). Interestingly, under the former "latitudinal" hypothesis, clines in climate-related and defense-related traits should be matched, while under the latter "range center" hypothesis, climate-related traits should directionally relate to latitude, but the defense-related traits should peak at intermediate latitudes (i.e., near the range center). In either case, the joint evolution of growth and defensive traits along biogeographical gradients constitutes a remarkable gap in our understanding of plant adaptation.

The above logic assumes that growth and defense are able to respond independently to selection, but in fact the growth and defense strategies of plants are evolutionarily intertwined in at least two ways. First, defense is hypothesized to be costly and to compete with growth for resources (Simms 1992, Agrawal et al. 2010), and this should limit maximal adaptation, maintain variation, and promote phenotype-environmental matches. Second, plant growth rate has been predicted to evolve in concert with the resource availability of environments (slower growth rates in lower-resource environments), and this is thought to set the template for defensive adaptations (Coley et al. 1985, Fine et al. 2004). In particular, because the replacement value of tissues is higher for slower-growing plants, intrinsically slow-growing plants are somewhat paradoxically predicted to invest in greater levels of defense than fastergrowing plants (even though low resource availability might make such investment more costly). Biogeographic clines in resource availability and biotic interactions may therefore conspire to impact growth and defense strategies either concordantly or antagonistically. For instance, if both resource availability and the intensity of herbivory increase at lower latitudes, there may be selection for increased growth rates and defense at such latitudes, but the joint evolution of these traits may be constrained. Thus, an integrative approach to studying plant strategies along ecological gradients would address 

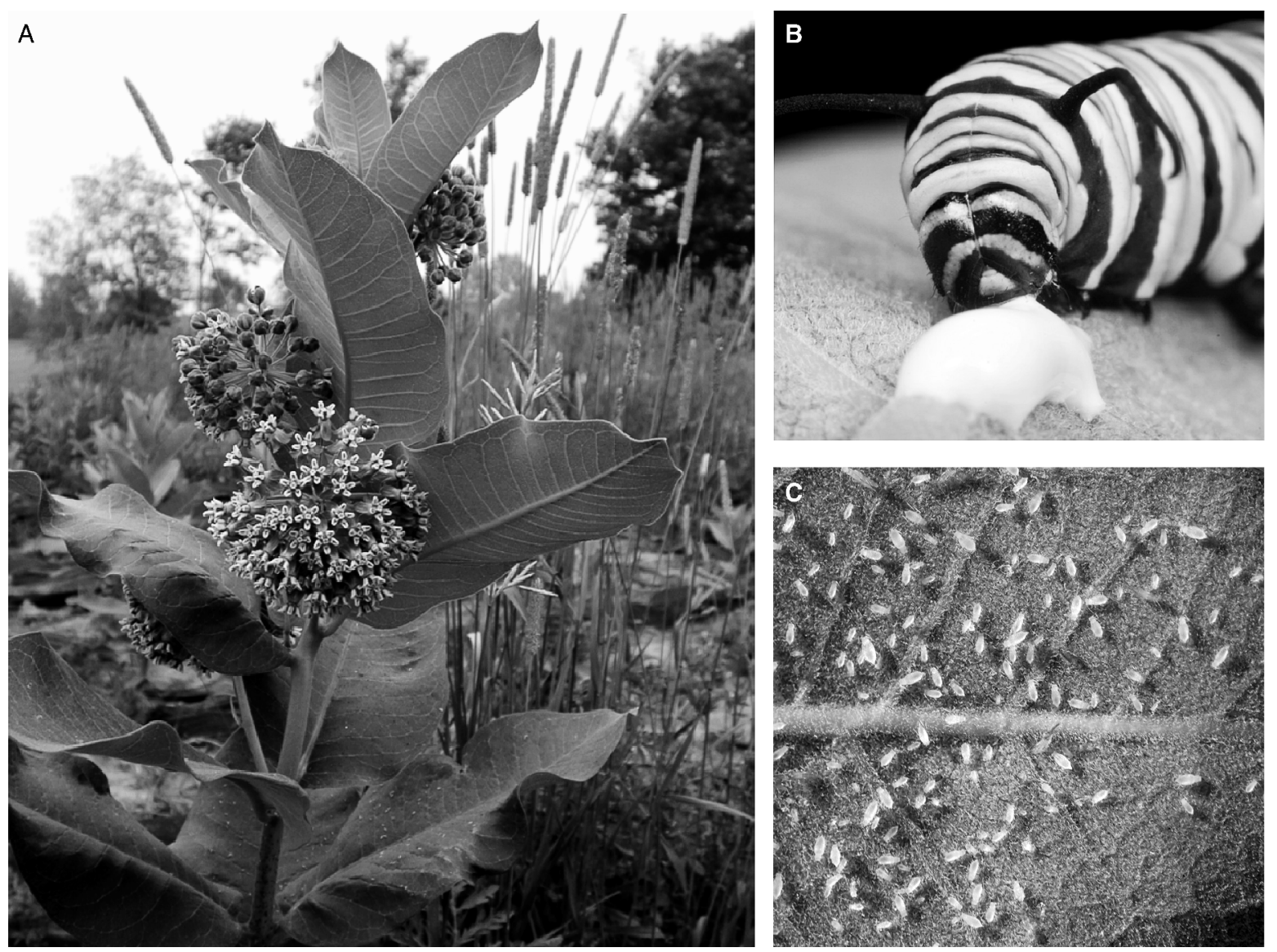

FIg. 1. (A) Common milkweed (Asclepias syriaca) growing in our New York common garden. (B) A late-instar monarch butterfly caterpillar (Danaus plexippus) biting an $A$. syriaca leaf and experiencing the outflow of the plant's defensive latex. (C) Immatures of Myzocallis asclepiadis on the underside of an A. syriaca leaf. All adults of this aphid are winged.

long-standing hypotheses about the population biology of widely distributed organisms and the evolutionary ecology of their interactions with the abiotic and biotic environment (Hunter et al. 1996, Agrawal 2011).

Here we focus on how growth and defense traits of native common milkweed (Asclepias syriaca; Fig. 1) have adapted along a latitudinal gradient in response to abiotic (climate) and biotic (herbivory) factors. We used common garden experiments in conjunction with observations of natural populations to investigate genetically based latitudinal clines in plant allocation. Specifically, we grew common milkweed in three geographic locations from 22 populations spanning the approximate range of the species, over $10^{\circ}$ of latitude $(>1500 \mathrm{~km})$. We report on clines in growth and defense traits to disentangle how the abiotic and biotic environments may impose natural selection for generating these latitudinal gradients. We also conducted surveys of herbivores and herbivory damage in multiple populations at the edges and center of the species range to address the role of altered biotic interactions in generating the genetically based clines we observed in the common gardens.

\section{Materials And Methods}

\section{Natural history}

Common milkweed, Asclepias syriaca L. (Apocynaceae), is a perennial plant whose native range is thought to extend from New Brunswick, Canada to Virginia, USA, and as far west as Kansas and North Dakota (Woodson 1954). Near the center of its range in central New York, plants typically emerge from perennial rootstocks in late May, flower in late June through most of July, and mature fruits and disperse seeds well into October. In the past few decades, A. syriaca has expanded its range farther north in Canada and as far south in the United States as Georgia and Louisiana, probably due to human-caused disturbance and transport (Wyatt et al. 1993, Wyatt 1996). Asclepias syriaca reproduces both asexually via underground rhizome-like stems and sexually via perfect flowers. After pollination, A. syriaca produces fruit pods (follicles). Because seeds of $A$. syriaca are sired by insertion of a pollinium, all 


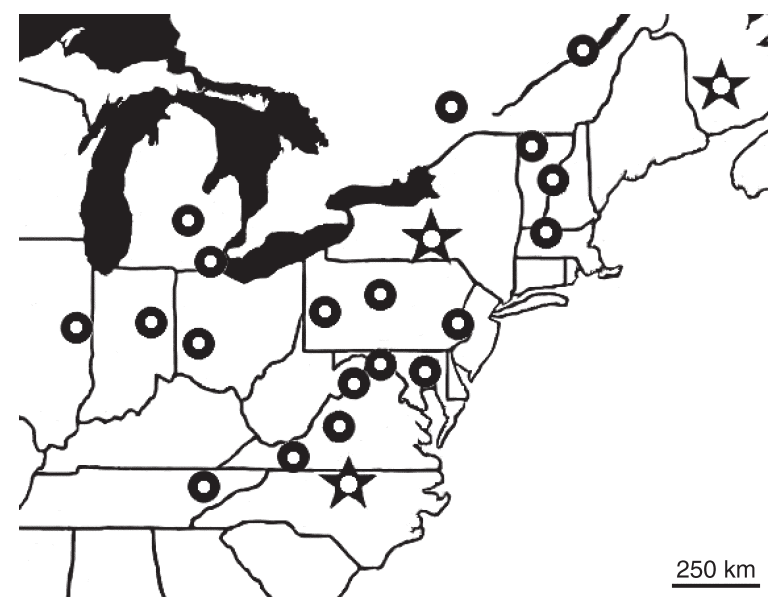

FIG. 2. Locations of A. syriaca parental seed stock. The three stars indicate the three common gardens (and also represent collection sites).

seeds from one follicle have the same sire and represent a full-sibling genetic family (Gold and Shore 1995).

Asclepias syriaca produces a suite of well-known antiherbivore defenses (Agrawal 2005). These traits are effective against many generalist herbivores, and milkweeds are rarely damaged by vertebrate browsing, or by generalist insects such as grasshoppers (see more on this subject in Vertebrate herbivory and generalists). The most important agents of herbivore damage to $A$. syriaca are $\sim 12$ species of specialist herbivores. In particular, three aphids (Smith et al. 2008), three beetles (Agrawal and Van Zandt 2003, Agrawal 2004, Van Zandt and Agrawal 2004), two lygaeid bugs, a leafmining fly, and three lepidopterans (Agrawal and Malcolm 2002, Agrawal 2005) attack the plant near the center of its range in central New York. Asclepias syriaca employs constitutive and induced plant defenses, the most potent of which are latex (Zalucki and Malcolm 1999, Van Zandt and Agrawal 2004, Agrawal and Konno 2009) and cardiac glycosides (cardenolides) (Malcolm 1991, Agrawal 2005). Latex in A. syriaca is transported throughout the plant by specialized canals (laticifers), and exudes from plant tissue upon damage (Fig. 1). Milkweed latex is extremely gummy, which can result in a physical barrier to feeding, and in addition has several concentrated toxins (Agrawal and Konno 2009). Cardenolides are toxic steroids that disrupt cellular sodium-potassium pumps, and are present in all plant tissues, including latex (Malcolm 1991). Other defensive traits that may limit herbivory are leaf toughness, trichomes, volatile organic compounds, and nitrogen content (Agrawal 2005, Mooney et al. 2010). Each of these traits shows heritable variation among full-sib genetic families within populations (Agrawal 2004, Mooney and Agrawal 2008). Despite sequestering plant defenses, specialist herbivores of milkweed are not known to cue in on, or be stimulated by, the main defensive traits (latex, cardenolides, or trichomes) (Agrawal 2005, Mooney et al. 2010).

Vertebrate herbivory and generalists.-Most research on interactions between Asclepias and herbivores has been conducted with specialist insect herbivores. This excludes the literature on livestock poisoning, which can occur, but is uncommon with Asclepias spp., and occurs in an unnatural setting (Knight and Walter 2001). We focus here on specialist insect herbivores for three reasons. First, most attacks on plants in natural populations are from specialist insect herbivores (E. C. Woods, A. P. Hastings, N. E. Turley, S. B. Heard, and A. A. Agrawal, personal observations). Second, specialist insect herbivores impose natural selection for defenses such as latex on A. syriaca (Agrawal 2005), and plant defensive traits have imposed natural selection for counter-adaptations in these specialist insects (such as trenching of laticifers, altered sodium pumps, and other adaptations [Agrawal and Malcolm 2002, Agrawal and Konno 2009]). Third, our personal observations indicate that in meadows where deer and rabbits frequently browse plants in the Asteraceae and Onagraceae, they rarely touch $A$. syriaca.

Nonetheless, caveats are important here. We have frequently observed that young transplanted plants (i.e., from growth chamber starts) are subject to browsing by rabbits. This tends to be transient, and typically on plants $<30 \mathrm{~cm}$, but nonetheless can have impacts on the plants, which quickly regrow with new stems following browsing. Regrown plants typically are not rebrowsed. Generalist slugs and snails can be highly abundant in moist old-fields where $A$. syriaca is common, and can typically be found grazing the oldest, often senescent leaves of A. syriaca. However, in rare cases, these mollusks skeletonize younger leaves. In this study we report on the frequency of vertebrate and mollusk attack in our experiments. Because both vertebrate browsing and molluscan grazing leave distinct signs (clipped meristems and shiny slime trails, respectively), we were able to track their damage.

\section{Seed collections}

Because we were interested in north-south clinal variation in $A$. syriaca, we (and colleagues, see the Acknowledgments) collected seeds from 22 natural populations. Most populations occurred in old fields or along roadsides. Sampled populations ranged through Eastern North America, stretching as far north as Quebec City, Quebec, Canada, as far south as Knoxville, Tennessee, USA, and as far west as Urbana, Illinois, USA (Fig. 2; Appendix A). Seeds from a single population collected south of Knoxville (Bishop, Georgia, USA) failed to germinate. Three to ten pods (fullsibling families) were collected from each population (mean $=6$ pods) from plants separated by at least $5 \mathrm{~m}$. Before seeds were planted, we counted the number of seeds per pod and weighed all the seeds to estimate the mean mass of individual seeds per pod. 


\section{Climatic data}

We compiled climatic data for the 22 populations using the most recent climate normals (i.e., 30-year averages) 1971-2000 from NOAA's National Climate Data Center and Environment Canada (available online), ${ }^{7,8}$ following methods outlined by Montague et al. (2008). The raw data came from the climate stations in closest proximity to the collection sites, and all stations but one conformed to World Meteorological Organization standards. Light, temperature, growing degree unit accumulation (an estimate of growing season developed for agricultural crops), and precipitation are major components of the climatic differences across our sample populations and may influence plant growth strategy (Montague et al. 2008). Latitude was a strong predictor of most but not all climatic variables. Using Pearson correlations for the climate variables for each site, we found that latitude was highly correlated with mean annual temperature (range $4^{\circ}-14^{\circ} \mathrm{C}, n=22, r=$ -0.94, $P<0.001)$ as well as three other measures of temperature and growing season (Appendix B). Annual precipitation was not correlated with latitude (range 79$135 \mathrm{~cm}, n=22, r=-0.34, P=0.12$ ), and because precipitation is an important variable that may influence plant allocation (and differed nearly twofold among our common milkweed populations), we included both latitude and total annual precipitation in multiple regression analyses as predictors of plant traits.

\section{Common garden experiments}

To evaluate the genetic basis of plant growth and defense trait variation, we established four common gardens: two near the center of the range (Ithaca, New York, USA), one near the northern range edge (Fredericton, New Brunswick, Canada), and one near the southern range edge (Raleigh, North Carolina, USA).

Main common garden in New York.-In May 2008, we germinated seeds from 3-5 full-sibling families from each population (103 families in total) by placing them between layers of moist paper towels in sealed petri dishes and incubating them at $30^{\circ} \mathrm{C}$ for five days. We then planted up to 10 seedlings from each family in plug trays filled with potting soil. Trays were placed in full sun on an open-air rooftop patio on the Cornell University campus, and seedlings were watered as needed. We transported the seedlings to the field site in Dryden, New York, USA 11 days after planting and kept them in a shade house for one week, until they were planted in the field on 4 June.

The field plot was a mesic abandoned agricultural field. To prepare the plot, we sprayed it with herbicide and tilled the soil two weeks prior to planting. In a completely randomized design, we planted milkweeds in 4-L plastic pots fully sunk into the ground and filled

\footnotetext{
${ }^{7}$ http://www.ncdc.noaa.gov/oa/ncdc.html

${ }^{8}$ www.weatheroffice.gc.ca/canada_e.html
}

with field soil. Pots were used to restrict clonal growth of A. syriaca roots (Agrawal 2004). We watered plants only early in the season to help them establish, and we weeded the plot periodically through the growing season. By mid-July, 418 plants had established, with nearly 20 plants and three to five genetic families per population.

Plant traits and insect assays.-In the first growing season we measured five plant traits associated with resistance to herbivory: latex exudation, percent leaf water content, specific leaf area (area/dry mass), trichome density, and cardenolide concentration (Van Zandt and Agrawal 2004, Agrawal 2005, Bingham and Agrawal 2010). While no herbivores were placed on the plants, we recorded natural herbivory and the abundance of insect herbivores. Some plants were grazed by invertebrates (typically damage by monarch Danaus plexippus caterpillars, adults of the red milkweed beetle Tetraopes tetraophthalmus, or mollusks), infested by aphids (Aphis nerii), or browsed, typically by rabbits. Nearly all browsed plants regrew new stems.

We measured latex on each plant by cutting off the tip $(2-3 \mathrm{~mm})$ of the uppermost fully expanded leaf and letting latex exude onto a 1-cm disk of pre-weighed filter paper. When the latex stopped flowing, the disc was removed and placed into a pre-weighed $2-\mathrm{mL}$ microcentrifuge tube for subsequent weighing. We have previously found wet and dry mass of latex to be strongly correlated, and wet latex to be a strong predictor of herbivore growth rate and insect abundance in the field (Van Zandt and Agrawal 2004, Agrawal 2005).

We assessed specific leaf area, water content, and trichome density on each plant by taking a $6 \mathrm{~mm}$ diameter leaf punch, centered along the midrib at the tip of the leaf opposite that from which latex was collected. Before the discs were dried, we counted trichomes on the bottoms of the leaf discs under a dissecting microscope.

To assess cardenolide concentration, we collected the two uppermost, fully expanded leaves from which other measurements were recorded. These leaves were frozen $\left(-80^{\circ} \mathrm{C}\right)$ and dried at $45^{\circ} \mathrm{C}$, and for each sample, $75 \mathrm{mg}$ of tissue was ground using a mixer-mill (Retsch, Haan, Germany) with 3-mm stainless steel beads in a microcentrifuge tube. Extraction and analysis of the cardenolides using HPLC followed the methods of Rasmann et al. (2009). We limited cardenolide analysis to 130 samples, with an average of 5.9 plants from each of the 22 populations. In all cases where we subsampled the plants, we took care to maximize the sampling of different genetic families from each population.

During the second growing season (2009), we took an early (3 June) and a late (13 August) measurement of height and stem number for each plant. Our early season measure of plant emergence from perennial root stocks gave an indication of phenology, because early-emerging plants were taller at this time, and populations differed dramatically in this trait (see Results). Later in the 
season, plant height was not correlated with earlyseason height $(n=22, r=-0.20, P>0.25)$ and did not differ between populations $\left(F_{21,156}=1.54, P>0.05\right)$. We measured cardenolides in the second year of plant growth, as outlined above, except that we used $100 \mathrm{mg}$ of tissue in chemical analyses ( $n=193$, an average of 8.8 plants from each of the 22 populations).

During this second growing season, plants became naturally infested with aphids (Myzocallis asclepiadis), which we counted on a subset of plants ( $n=156$ plants, $\sim 7$ plants for each of the 22 populations). In addition, we performed a bioassay using neonate monarch butterfly caterpillars (Danaus plexippus) to evaluate insect growth and thus quantify the total effectiveness of defensive traits of the milkweed plants. Here again we used a subset of the plants $(n=187, \sim 8.5$ plants from each of the 22 populations). Two freshly hatched $D$. plexippus caterpillars were placed on the apical leaves of each plant (13 August) and protected using a spun polyester sleeve. The caterpillars were allowed to feed for six days, removed from the plants, and weighed. If two caterpillars were recovered from an individual milkweed, their mass was averaged for a single data point; where no caterpillars were recovered, the replicate was excluded.

Second New York common garden; destructive harvest.-We established a second garden using the same $A$. syriaca populations and families for a destructive harvest to examine above- and belowground vegetative allocation. In the second week of June 2008, seeds from each family were germinated and planted in $500-\mathrm{mL}$ pots filled with a 50/50 mixture of field topsoil and potting mix. This mixture was used to ensure exposure to the microbial community from field soil, while facilitating root washing to estimate belowground biomass. Here we focused on population variation $(n=$ 22) with at least three genetic families represented from each population, but low replication within families (total $n=204$, a mean of 9.2 plants per population for most traits). The plants were randomized on an open-air rooftop patio and watered throughout the season as needed. After 82 days of growth, we estimated latex exudation (see Plant traits and insect assays), and then harvested all plant material, washed roots free of soil, weighed total above- and belowground dry biomass (after drying at $45^{\circ} \mathrm{C}$ ), estimated root-to-shoot ratio, and recorded the number of root buds (i.e., asexually reproducing dormant buds).

New Brunswick and North Carolina common gardens.- In 2009, we established smaller common gardens near the range edges in Fredericton, New Brunswick, Canada ( $n=127$ plants from 12 populations) and Raleigh, North Carolina, USA ( $n=108$ plants from 11 populations). Populations were chosen to span the complete latitudinal range, and 11 of the chosen populations were common to both gardens (Appendix A). Plots were prepared as in New York and plants were again restricted in their clonal growth, here using 4-L water-permeable cloth tree bags (High Caliper Growing, Oklahoma City, Oklahoma, USA), which were sunk below ground level and filled with local field soil. Plants were grown from seed in growth chambers for one month, the aboveground tissue was clipped, and the plants were planted in the field during summer. This procedure was used to allow transplanted plants to regrow aboveground tissues acclimated to field conditions. In 2010, new stems naturally emerged from dormant root stocks at both sites, and we measured early-season height as an indication of phenology. We also sampled latex and measured final aboveground biomass as dry stem biomass (because some leaves had dropped or senesced). For $A$. syriaca, stem mass correlates well with total aboveground biomass $(n=$ $50, r=0.94, P<0.001)$.

All of our common gardens were open to browsing by small mammals (rabbits, groundhogs, voles, and others) and all invertebrates. The New York common garden was fenced and inaccessible to deer, but no fencing was applied in the New Brunswick common garden. Although the North Carolina common garden was protected by an electric deer fence, this fence was breached by deer several times over the two years of the study. We have no evidence that deer herbivory impacts milkweed in natural populations (see also Results).

Statistical analyses.-We analyzed plant and insect traits using SYSTAT, version 12 (Systat 2007), with an ANOVA model including population $(n=22)$, and, when possible, full-sibling genetic family nested within population (range 3-5). Family was only included in analyses when all plants were measured in the main New York common garden in 2008, where replication was sufficient to include this term. For traits in which fewer plants were measured, we were careful to sample across all genetic families, but could not include this term in the analysis. In all subsequent analyses, population was considered the unit of replication and family variation was averaged within populations. In addition, for the 2008 data, we included natural levels of herbivory (three discrete levels: none, invertebrate grazing, or browsed by mammals and regrown) and aphid infestation (presence or absence) as additional predictors in the ANOVA model.

Genetically based clines in phenotypic traits were assessed with multiple regression, using latitude and precipitation as predictors. Alternative analyses using distance from range center (estimated near Pittsburgh, Pennsylvania, USA) had much less predictive power and are not presented here. To assess phenotypic plasticity and local adaptation in the range edge common gardens (2010), we conducted analyses (MANCOVA, followed by univariate ANCOVAs) on early-season height, number of stems, latex exudation, and final stem mass as predicted by latitude and precipitation at the collection sites and common garden location. All interaction terms were included except the three-way 
interaction, which never approached statistical significance.

To address consistency of the clines across common gardens (i.e., plasticity in the genetically based phenotypic clines), we focused on the northern and southern common gardens, where we measured the same four traits in the same year. Because the New York common garden was established with slightly different protocols, and a year earlier, it could not be directly compared to the northern and southern common gardens. Some caution in interpretation is thus in order because the two sites compared were not replicated at their respective latitudes. We used ANCOVA to address interactions between the common garden site (New Brunswick and North Carolina) and the two predictors (latitude and precipitation of the source populations) for standardized (by the mean of that common garden) trait means from each population ( $n=11$ populations in each garden). Values were standardized to avoid confounding influence of plasticity in the traits per se, or of slight differences in planting protocols. In other words, we focused on whether the slope of the relationship between the predictors and mean population phenotype differed between the two common gardens. In addition, we used regression relationships between traits and growth, analogous to selection analyses (Lande and Arnold 1983), to assess the factors that favored growth in the different common gardens. Because $A$. syriaca is a longlived perennial with both aboveground sexual and belowground asexual reproduction, these regressions do not provide good estimates of lifetime selection, but nonetheless reveal important aspects of performance at early life stages.

Because we found significant biogeographic clines in growth and defense traits, we attempted to disentangle the causes of these relationships with two path analyses using the RAMONA module of SYSTAT. In the first, we used latitude and precipitation as predictors of seed mass, growth, and latex exudation, and assessed the impact of these factors on caterpillar performance, while accounting for potential intercorrelations among the traits ( $n=22$ population means). In the second, we used latitude and precipitation as predictors of seed mass, growth, trichomes, and water content, and assessed the impact of these factors on aphid abundance. We used different sets of plant traits in the two analyses because we had limited power and were unable to include all variables (based on population being the unit of replication, $n=22$ ). Instead, we built each path analysis around significant (or marginally significant) predictors from our initial analyses. We employed a correlational matrix, maximum Wishart likelihood, and 95\% confidence intervals on the path coefficients.

Natural population surveys.-In both 2009 and 2010, we conducted surveys of plant damage on natural populations of $A$. syriaca from five sites each in the surroundings of Ithaca, Fredericton, and Raleigh. Within each of the three survey regions, sites were at least $3 \mathrm{~km}$ apart, but often $>15 \mathrm{~km}$ apart. Surveys were conducted at the peak of the growing season at each site. For 25 nonneighboring stems in each site (or slightly fewer in smaller populations) we recorded the percentage of leaves with chewing damage and the identities of all insects present on plants. We were able to differentiate between damage due to the various milkweed specialists and generalist mollusks. We used site means for leaf damage and insect diversity to assess differences in both years (total $n=15$ ) using repeated-measures MANOVA.

\section{RESUlts}

\section{Population variation and clines in growth and defense traits}

All but one of the 13 traits measured showed evidence of interpopulation differences, typically with greater than twofold variation in trait values (Table 1). Individual seed mass and seed number per pod (both measured from the original collections in the parent populations) varied substantially among populations (Table 1), and individual seed mass showed a latitudinal cline with increasing mass at higher latitudes (Table 2; Appendix D). We found no relationship between individual seed mass and seed number per pod at the population $(n=22, r=0.060, P=0.79)$ or individual level ( $n=133, r=0.070, P=0.42$ ). For the 11 traits measured in common gardens, the only trait not to show population variation was leaf trichome density, for which the population effect was marginal (Table 1).

Several aboveground plant traits showed geographical clines. Our measures of aboveground biomass accumulation showed consistently lower biomass of plants from higher-latitude populations, irrespective of growing location (Fig. 3). In all three common gardens, plants experienced $\sim 5 \%$ decline in biomass per degree of latitude and $>50 \%$ decline across the studied geographic range. Among other traits measured in the New York common garden, latex production increased with collection latitude and precipitation (Fig. 4), but other foliar traits (trichomes, specific leaf area (SLA), water content, and cardenolides) showed no clines (Table 2). The cline in latex was not significant in either of the range edge common gardens (Table 2). Herbivory in the New York common garden (2008) was associated with altered plant traits (latex, trichomes, SLA, and water content; Appendix C); in particular, as we have reported from experimental studies, grazing by invertebrates induced latex production by $55 \%$ (Bingham and Agrawal 2010), while vertebrate browsing decreased trichome densities by $60 \%$.

Allocation to underground traits also showed substantial clines. The number of root buds per plant increased in higher-latitude populations (Table 2, Fig. 5 ), with a $\sim 6 \%$ increase in root buds per degree of latitude and $>75 \%$ increase across the studied geographic range. In the second year of plant growth, this cline in root buds drove a tendency for the number of 
TABLE 1. The effects of population origin on plant characteristics of Asclepias syriaca.

\begin{tabular}{|c|c|c|c|}
\hline Experiment and trait & Population range & Population $F$ & Family $F$ \\
\hline \multicolumn{4}{|l|}{ Parental stock } \\
\hline Seed number (115) & 125-242 seeds/pod & $4.30 * * *$ & \\
\hline Individual seed mass (115) & $3.49-7.05 \mathrm{mg}$ & $3.14 * * *$ & \\
\hline \multicolumn{4}{|l|}{2008 New York destructive harvest } \\
\hline Latex (336) & $1.65-3.24 \mathrm{mg}$ & $1.45 \dagger$ & \\
\hline Shoot biomass (182) & $0.316-0.802 \mathrm{~g}$ & $4.52 * * *$ & \\
\hline Root biomass (182) & $0.728-1.33 \mathrm{~g}$ & $2.80 * * *$ & \\
\hline Total biomass (182) & $1.16-2.00 \mathrm{~g}$ & $3.24 * * *$ & \\
\hline Root-to-shoot ratio (182) & $1.51-3.48$ & $4.95 * * *$ & \\
\hline Root buds (182) & $14.5-32.1$ buds & $2.43 * *$ & \\
\hline \multicolumn{4}{|l|}{2008 New York common garden } \\
\hline Latex $(312)$ & $0.681-4.01 \mathrm{mg}$ & $3.74 * * *$ & $2.08 * * *$ \\
\hline Trichomes (312) & $510-883 / \mathrm{mm}^{2}$ & $1.54 \dagger$ & 1.20 \\
\hline Specific leaf area (312) & $22.2-28.3 \mathrm{~mm}^{2} / \mathrm{mg}$ & $1.82 *$ & $1.37 *$ \\
\hline Water content $(312)$ & $78.7-81.8 \%$ & $2.42 * *$ & $1.36^{*}$ \\
\hline Amount of cardenolides (103) & $0.138-0.597 \mu \mathrm{g} / \mathrm{mg}$ dry mass & $2.38 * *$ & \\
\hline \multicolumn{4}{|l|}{2009 New York common garden } \\
\hline Early-season height (461) & $4.76-20.8 \mathrm{~cm}$ & $2.58 * * *$ & $1.35^{* *}$ \\
\hline No. stems (461) & $0.929-5.18$ stems & $3.41 * * *$ & $1.58 * *$ \\
\hline Amount of cardenolides (170) & $0.811-1.82 \mu \mathrm{g} / \mathrm{mg}$ dry mass & $4.18 * * *$ & \\
\hline \multicolumn{4}{|c|}{2010 New Brunswick common garden } \\
\hline Early-season height (105) & $47.1-87.4 \mathrm{~cm}$ & $1.95 *$ & \\
\hline No. stems (115) & $1.20-2.33$ & 1.31 & \\
\hline Stem biomass (115) & $0.131-0.542 \mathrm{~g}$ & $4.14 * * *$ & \\
\hline Latex (108) & $0.523-2.38 \mathrm{mg}$ & $4.30 * * *$ & \\
\hline \multicolumn{4}{|c|}{2010 North Carolina common garden } \\
\hline Early-season height (94) & $5.56-13.7 \mathrm{~cm}$ & $3.39 * *$ & \\
\hline No. stems (94) & $1.10-2.36$ & $2.01 *$ & \\
\hline Stem biomass (97) & $2.28-21.3 \mathrm{~g}$ & $6.66 * * *$ & \\
\hline Latex (104) & $2.58-7.13 \mathrm{mg}$ & $2.09 *$ & \\
\hline
\end{tabular}

Notes: Parental seed stock was collected from populations along a latitudinal gradient from Quebec City, Quebec, Canada, in the north to Knoxville, Tennessee, USA, in the south, and grown in field common gardens (Fig. 2). Seed data were analyzed using the parental stock (not a common garden), with each within-population family contributing one data point (i.e., seeds from one fruit). For the New York common garden, $n=22$ populations; full-sib family was nested within each population (mean of 4.6 families per population). Analysis of family was not possible in other analyses because there was little replication within families. Naturally occurring herbivory was recorded in the 2008 New York common garden and included in the complete analysis (Appendix B). The New Brunswick and North Carolina common gardens were represented by a subset of the 22 populations (12 and 11 populations, respectively). Denominator df values are indicated in parentheses following the traits. Values in bold are statistically significant (ANOVA).

* $P<0.05 ; * * P<0.01 ; * * *<<0.001 ; \dagger P<0.1$.

emergent stems to increase with source latitude (significant in the New York common garden, marginal in New Brunswick, and not significant in the North Carolina garden; Table 2). The three common gardens did not differ in mean numbers of stems emerging in the second year of growth $\left(F_{2,21}=0.090, P=0.91\right)$. Although root biomass did not vary clinally, the cline in shoot mass caused root-to-shoot ratio $(R / S)$ to show a greater relative belowground investment at higher latitudes (Fig. 5), and higher precipitation showed a similar but weaker effect.

While our data suggest that the sample populations were genetically differentiated, we also found evidence for plasticity in the regulation of latitudinal clines when statistically comparing the New Brunswick and North Carolina common gardens. In a MANOVA analysis of the same four traits from 11 populations, measured in the same year, there was both a significant latitude-bygarden and precipitation-by-garden interaction (Table
3). However, the only detectable interaction for individual traits was that between latitude and garden for early stem height (Table 3). In this case, a cline in phenology was detectable in North Carolina, but not in New Brunswick (Table 2; Appendix E). A cline showing genetically based earlier phenology in higher-latitude (and higher-precipitation) populations was also evident in the New York common garden (Table 2, Fig. 6), indicating that this trait cline was environmentally obscured at the highest-latitude garden only.

Despite plasticity in the expression of the cline, an estimate of selection (the relationship between phenology and growth) was consistent with early phenology being adaptive at higher, but not lower, latitudes. In particular, the slope of the relationship between phenology and growth was markedly positive $(m=2)$ in New Brunswick, but negative $(m=-0.8)$ in North Carolina $\left(F_{1,18}=6.01, P=0.025\right.$, Fig. 7$)$. A weaker trend for reversal in the benefits of multiple stems was also 
TABLE 2. Analysis of population, latitude, and precipitation as predictors of plant characteristics of Asclepias syriaca population means using multiple regression.

\begin{tabular}{|c|c|c|c|c|}
\hline Experiment and trait & Overall model, $F$ ratio & $R^{2}$ & Precipitation (coefficient) & Latitude (coefficient) \\
\hline \multicolumn{5}{|l|}{ Parental stock $(n=22)$} \\
\hline Seed number & 0.049 & 0.005 & -0.16 & -0.672 \\
\hline Individual seed mass & $4.76^{*}$ & 0.33 & -0.01 & $0.157 *$ \\
\hline \multicolumn{5}{|c|}{2008 New York destructive harvest $(n=22)$} \\
\hline Latex & $3.33 \dagger$ & 0.26 & -0.010 & $0.060 \dagger$ \\
\hline Shoot biomass & $11.7 * * *$ & 0.55 & $-0.002 \dagger$ & $-0.028 * * *$ \\
\hline Root biomass & 0.258 & 0.026 & -0.002 & -0.006 \\
\hline Total biomass & $2.84 \dagger$ & 0.23 & -0.004 & $-0.034^{*}$ \\
\hline Root-to-shoot ratio & $11.2 * *$ & 0.54 & 0.014* & $0.129 * * *$ \\
\hline Root buds & $4.85 *$ & 0.34 & $0.18 \dagger$ & $1.193 * *$ \\
\hline \multicolumn{5}{|c|}{2008 New York common garden $(n=22)$} \\
\hline Latex & $4.66 *$ & 0.33 & $0.026 *$ & $0.120 *$ \\
\hline Trichomes & 0.030 & 0.003 & 0.069 & 1.782 \\
\hline Specific leaf area & 0.256 & 0.026 & 0.018 & 0.034 \\
\hline Water content & 0.313 & 0.032 & 0.010 & 0.030 \\
\hline Cardenolides & 1.79 & 0.16 & $<0.001$ & $0.013 \dagger$ \\
\hline \multicolumn{5}{|c|}{2009 New York common garden $(n=22)$} \\
\hline Early-season height & $4.02 *$ & 0.30 & $0.12 *$ & $0.593 *$ \\
\hline No. stems & $12.7 * * *$ & 0.57 & $0.037 *$ & $0.210 * * *$ \\
\hline Cardenolides & 0.094 & 0.10 & $<0.001$ & $<0.001$ \\
\hline \multicolumn{5}{|c|}{2010 New Brunswick common garden $(n=12)$} \\
\hline Early-season height & $3.93 \dagger$ & 0.47 & $-0.40 *$ & $-1.491 \dagger$ \\
\hline No. stems & $2.70 \dagger$ & 0.38 & 0.008 & $0.059 \dagger$ \\
\hline Stem biomass & $4.15 *$ & 0.48 & -0.004 & $-0.024 *$ \\
\hline Latex & 0.125 & 0.027 & -0.006 & -0.007 \\
\hline \multicolumn{5}{|c|}{2010 North Carolina common garden $(n=11)$} \\
\hline Early-season height & $3.85 \dagger$ & 0.49 & 0.038 & $0.443 *$ \\
\hline No. stems & 0.487 & 0.11 & -0.010 & -0.017 \\
\hline Stem biomass & $9.30 * *$ & 0.70 & -0.007 & $-1.223 * *$ \\
\hline Latex & 0.882 & 0.18 & 0.031 & 0.096 \\
\hline
\end{tabular}

Notes: Traits were significantly different among populations in the common gardens in all cases except for latex in the New York destructive harvest and number of stems in the New Brunswick common garden (Table 1). The number of populations sampled is indicated by sample size. Values in boldface type are statistically significant.

$* P<0.05 ; * * P<0.01 ; * * * P<0.001 ; \dagger P<0.1$.

seen (interaction between common garden and the slope of the relationship between stems and growth, $F_{1,18}=$ 3.20, $P=0.090$; see also Table 2). We found no evidence for such an interaction with latex $\left(F_{1,18}=0.473, P=\right.$ $0.500)$.

\section{Insect abundance and performance}

Although few herbivores colonized the New Brunswick common garden, the North Carolina garden was attacked, and plants from lower latitudes were more heavily colonized by herbivores than higher-latitude plants (significant MANOVA in Table 4, and significant and marginal clines for two herbivores). Nonetheless, when plant biomass was included as a covariate, these relationships disappeared, suggesting that slower-growing northern plants may have simply been smaller targets for herbivores (data not shown). Effects of latitudinal collection on herbivores in the New York common garden, however, were due to other factors (not plant size) as discussed in the next paragraphs.

In the New York common garden, in 2009, a milkweed specialist aphid (Myzocallis asclepiadis) was naturally abundant on plants, and showed larger populations on plant populations from lower latitudes and with lower annual precipitation (after including plant size as a covariate) (Table 4, Fig. 8). For each degree of lower latitude, plants accumulated $>7 \%$ more aphids $(>60 \%$ increase across the range of our source populations). The caterpillar growth bioassay in the New York garden showed a similar trend, with caterpillar mass being higher on plants from lower latitudes (a marginal effect) and with lower annual precipitation (Table 4, Fig. 8). Here, because caterpillars were placed on plants and were not food limited, plant size could not contribute to the effect.

To address the causes of the clines in insect abundance and performance in the New York common garden, we took two approaches. First, we conducted multiple regression analyses with the $\log$ of the mean aphid population abundance or caterpillar mass as the dependent variable and four or five predictors (latex, trichomes, cardenolides, leaf water content, and specific leaf area; but with latex excluded for aphids because they feed intracellularly and do not come into contact with latex). For aphids, trichomes (positively) and water content (negatively) impacted aphid populations: (anal- 

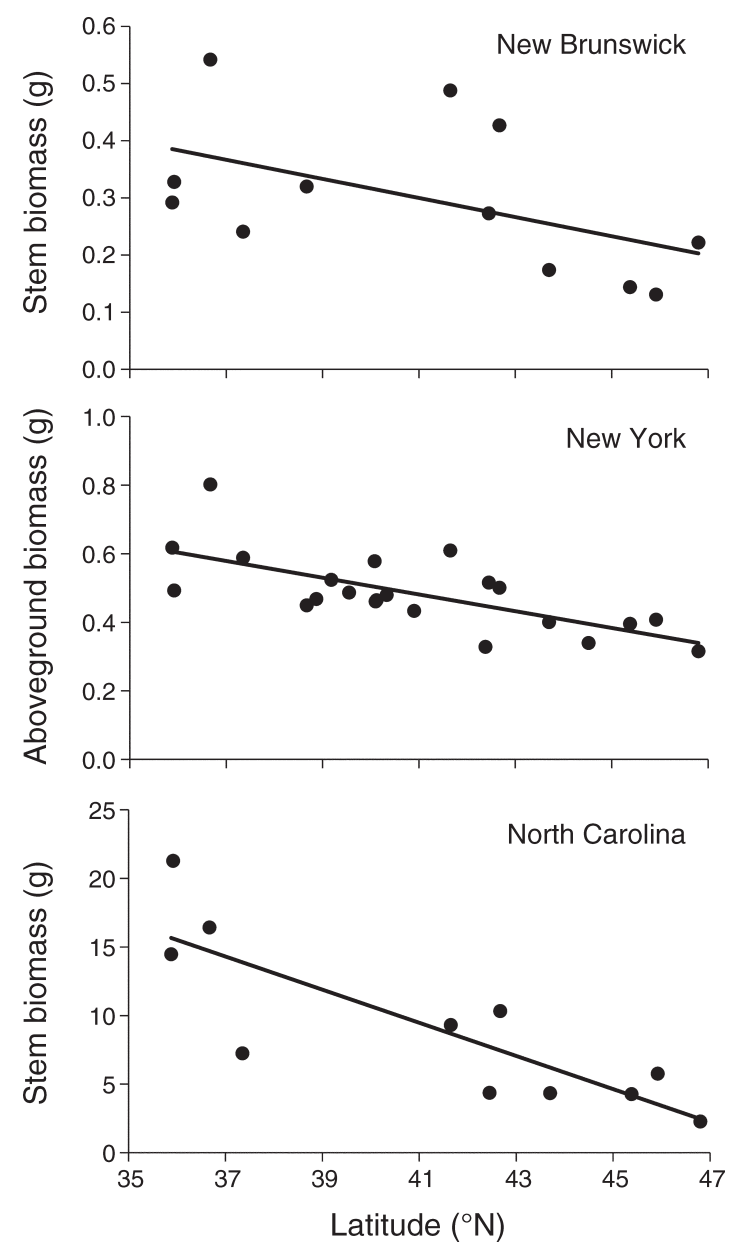

FIG. 3. Estimates of aboveground biomass $(n=11-22$ populations of $A$. syriaca) were consistently negatively correlated with latitude of the collection sites when plants were grown in three different common gardens spanning the latitudinal range (Table 2). Where aboveground biomass could not be measured due to leaf senescence, we measured stem mass, which is strongly correlated (see Methods). Shown are the raw data from simple regressions.

ysis on population means, model $r^{2}=0.45, F_{4,17}=3.51$, $P=0.029$; trichome coefficient $=0.007, t=2.69, P=$ 0.015 ; water content coefficient $=-1.65, t=-3.28, P=$ $0.004)$. Latex was the only significant predictor of caterpillar mass: (model $r^{2}=0.51, F_{5,16}=3.32, P=$ 0.030; latex coefficient $=-0.082, t=-3.78, P=0.002$ ).

Our second approach involved a path analysis presented in the following section.

\section{Synthesis via path analysis}

We conducted a path analysis on population means from the New York common garden to link this data and to explicitly address two issues: the importance of maternal effects via seed size on plant growth, and the potential role of a plant growth-latex trade-off in driving the patterns observed. Overall, significant path coefficients were moderately predictive and of similar magnitude $(\sim 0.5)$, with the strongest relationship being that between latitude and plant growth (Fig. 9). Although latitude had a strong impact on seed mass, plant growth, and latex, these relationships were largely independent, except that a positive relationship between seed mass and growth emerged despite latitude being positively associated with mass and negatively associated with growth. Thus, seed mass (and associated maternal effects) were clearly not responsible for the slower growth of high-latitude populations. Importantly, we found no evidence for a growth-latex trade-off, and latex was the primary driver of monarch butterfly growth, independent of plant growth or its unmeasured correlates (Fig. 9). We similarly found no relationship between plant growth and latex in the other two common gardens (New Brunswick, $n=12, r=-0.023$, $P=0.95$; North Carolina, $n=11, r=-0.073, P=0.83)$. A separate path analysis for aphid abundance in the New York common garden (Appendix F) revealed similar relationships among the predictor variables, but foliar water and trichomes exhibited independent effects on aphids from the residual effects of latitude and precipitation.

\section{Natural population surveys: herbivore abundance and diversity}

Although leaf damage varied considerably between years $\left(F_{1,12}=13.0, P=0.004\right)$, there was no populationby-year interaction $\left(F_{2,12}=0.799, P=0.47\right)$, with total herbivore damage (including all specialist insects as well as molluskan damage) over twice as high in New York than in either of the range-edge populations $\left(F_{2,12}=\right.$
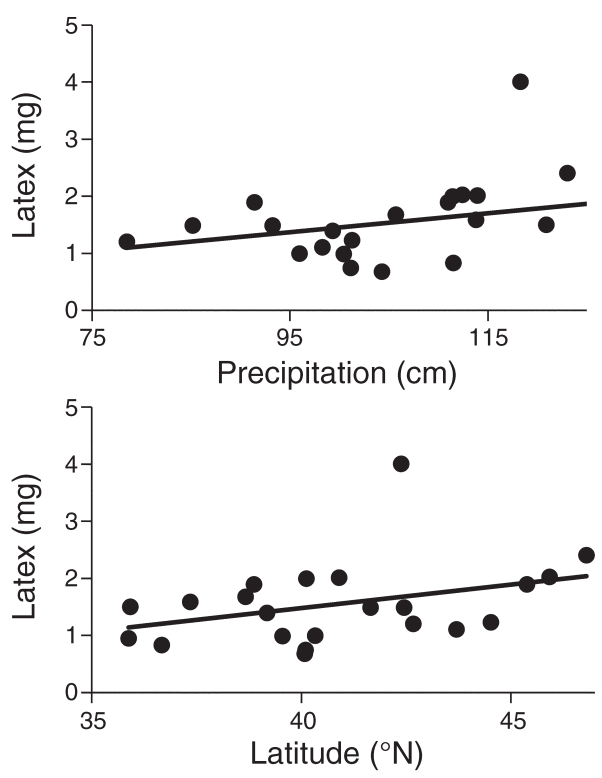

FIG. 4. Latex exudation of plants grown in the New York common garden was positively correlated with both the precipitation and latitude of the collection sites $(n=22$ populations of $A$. syriaca, Table 2). Shown are the raw data from simple regressions. 


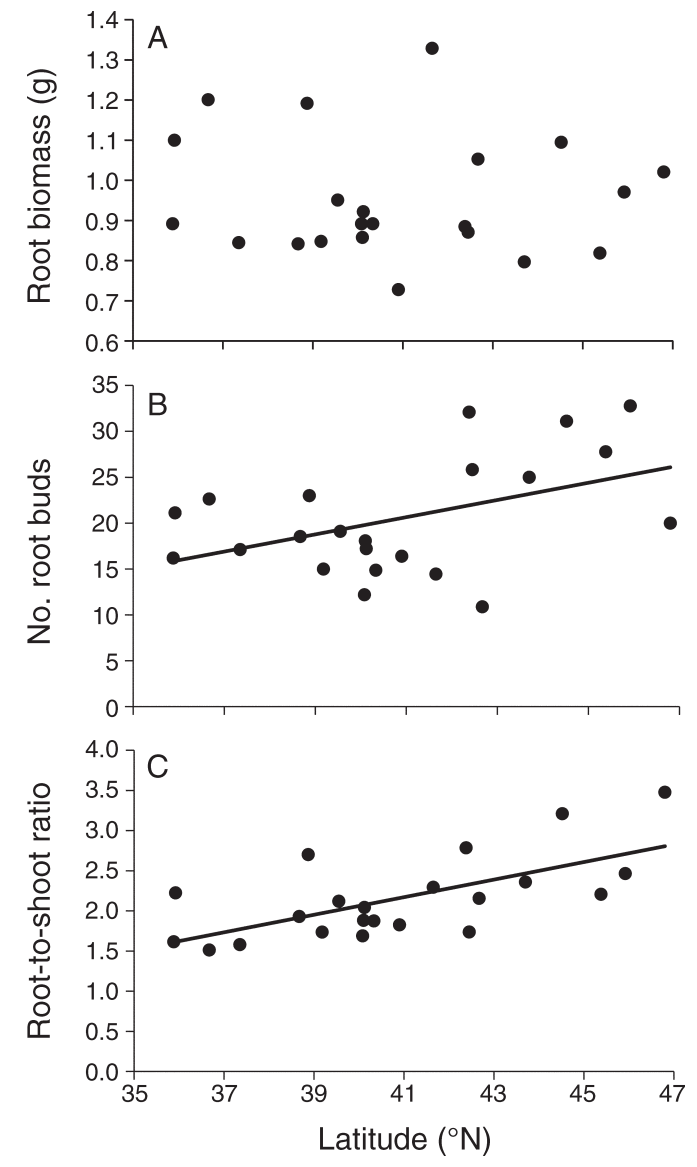

FIG. 5. There was no correlation between (A) root biomass and latitude of the collection sites, but (B) the number of root buds and $(\mathrm{C})$ the root-to-shoot ratio were positively correlated with latitude in our New York destructive harvest $(n=22$ populations of $A$. syriaca; Table 2). Shown are the raw data from simple regressions.

8.76, $P=0.005$, Fig. 10). Although mollusks were abundant in New Brunswick and New York, they were absent from our North Carolina censuses; among all of our censuses, mollusks were most damaging in New Brunswick, where their damage accounted for $9 \%$ of all

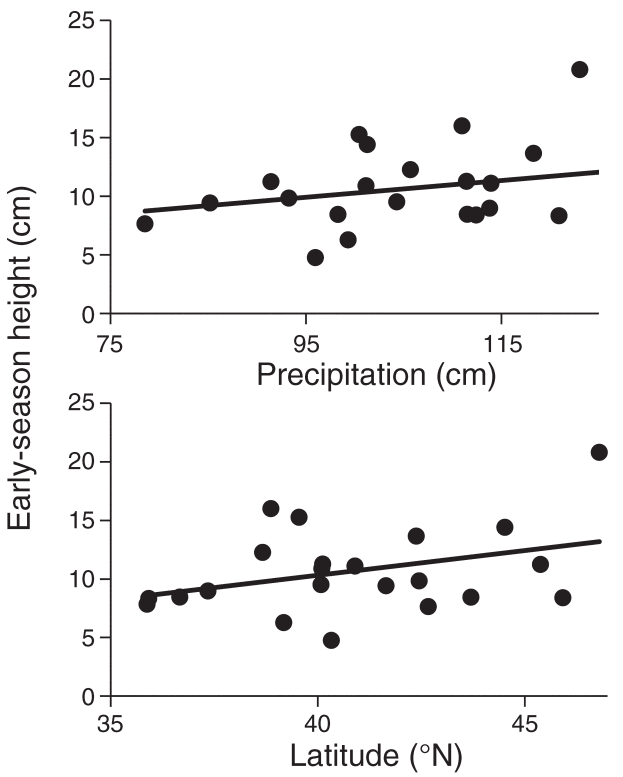

FIG. 6. Early-season height (an estimate of phenology) of plants grown in the New York common garden was positively associated with both the precipitation and latitude of the collection sites ( $n=22$ populations of $A$. syriaca; Table 2$)$. Shown are the raw data from simple regressions.

damaged leaves. The diversity of specialist insect herbivores was less variable by year (year, $F_{1,12}<$ $0.001, P=1.0$; population-by-year interaction, $F_{2,12}=$ $0.220, P=0.81$ ), but showed the same pattern as leaf damage across populations, with nearly twice the diversity in New York compared to the other two regions $\left(F_{2,12}=25.3, P<0.001\right.$, Fig. 10$)$.

Notes on vertebrate grazing and generalists.-Vertebrate grazing was uncommon in our experimental populations and surveys of natural populations (typically $<2 \%$ of plants damaged). We did not observe vertebrate damage in either the North Carolina or New Brunswick gardens. In our New York common garden, however, we observed substantial browsing, and this occurred immediately following transplanting in 2008 ( $13 \%$ of plants were browsed and all regrew new stems).

TABLE 3. Multivariate and univariate analysis of covariance for category effects.

\begin{tabular}{|c|c|c|c|c|c|c|}
\hline \multirow[b]{2}{*}{ Category } & \multicolumn{2}{|c|}{ MANOVA } & \multicolumn{4}{|c|}{ ANCOVA $F_{1,15}$} \\
\hline & Wilks' lambda & $F_{4,12}$ & Stem mass & Early-season height & No stems & Latex \\
\hline Garden $(G)$ & $<0.001$ & $<0.001$ & $<0.01$ & $<0.01$ & $<0.01$ & $<0.01$ \\
\hline Latitude $(L)$ & 3.36 & $10.1 * * *$ & $-3.93^{* * *}$ & 1.66 & 0.90 & -0.71 \\
\hline$G \times L$ & 3.13 & $9.40 * *$ & 1.13 & $-3.40 * *$ & 1.33 & -0.46 \\
\hline Precipitation $(P)$ & 0.213 & 0.640 & -1.44 & -0.22 & -0.15 & -0.05 \\
\hline$G \times P$ & 1.24 & $3.71 *$ & -1.18 & $-2.11 \dagger$ & 1.42 & -0.97 \\
\hline$L \times P$ & 0.768 & 2.30 & 0.87 & -1.04 & -0.59 & 1.38 \\
\hline
\end{tabular}

Notes: Categories analyzed were common garden (New Brunswick or North Carolina), latitude (11 populations planted at both sites), annual precipitation from the sampled populations, and all two-way interactions on four plant traits of Asclepias syriaca (total $n=22$ ). Subscripts of $F$ are degrees of freedom. Values were standardized (divided by the mean for each trait from each garden). For univariate analyses the $t$ ratio from the ANCOVA is reported. The three-way interaction was never significant and was excluded from the analyses. Values in boldface type are statistically significant.

$* P<0.05 ; * * P<0.01 ; * * * P<0.001 ; \dagger P<0.1$. 


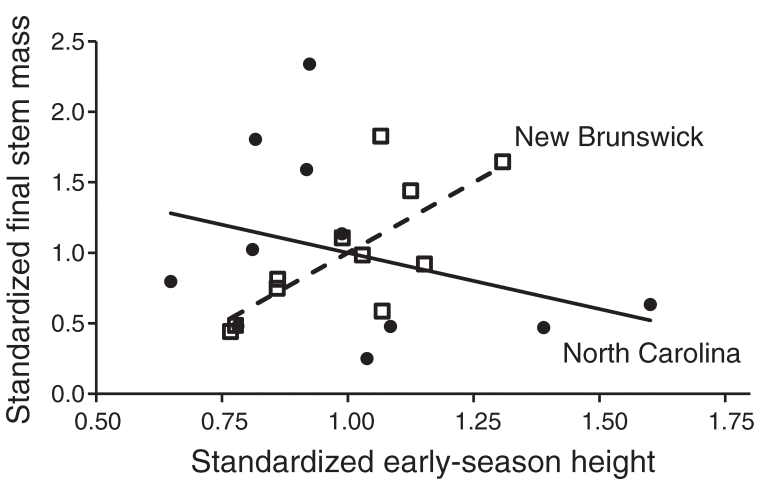

FIG. 7. A reversal in the impact of plant phenology (earlyseason height) on aboveground biomass accumulation in the New Brunswick vs. North Carolina common gardens for 11 populations of $A$. syriaca. There was a significant garden-byphenology interaction for effects on biomass $(P=0.025)$.

We emphasize that this appears to be a transient phenomenon associated with transplanting; in 2009 we observed $<7 \%$ of plants being browsed in the same common garden).

\section{Discussion}

We examined genetically based patterns of growth and defense of common milkweed from across the species range to evaluate (1) the independent evolution of growth and defense traits across the north-to-south gradient as predicted by latitudinal hypotheses, (2) joint evolution of growth and defense, as predicted by plant defense theory, and (3) the association of defense traits and herbivory with central vs. peripheral locations of the host plant range, as predicted by the distance from range center hypothesis. We found that plant traits associated with growth and phenology followed a latitudinal gradient, as did the production of a defensive secretion (latex). In common garden experiments, milkweed populations collected from higher latitudes showed evidence for slower growth, higher root: shoot ratios, earlier phenology, and higher latex exudation than lower-latitude populations. The cline in phenology contributed to local adaptation to climate, and the cline in latex enhanced defense against specialist monarch caterpillars, but no growth-defense relationship was implicated as a correlate of clinal evolution. Other traits (including cardenolides, trichomes, and specific leaf area) did not show clines. The extent of herbivory in natural populations roughly matched the distance from species range center hypothesis, as leaf damage and herbivore diversity were greatest in the middle of the species range. Nonetheless, levels of herbivory were not correlated with genetically based expression of defense. Below we further discuss each of the hypotheses tested.

\section{Genetically based geographic clines in growth}

Our most consistent result was that aboveground plant growth, as measured by shoot biomass accumulation, was lowest among high-latitude populations, and linearly increased in plants from lower latitudes. When we assessed growth as a function of distance from the range center, which corresponds to level of insect attack, there was no significant pattern (data not shown). Thus, geographically driven changing climate appears to be a driver of plant growth allocation. Despite extreme environmental differences between our common gardens, the tendency for lower-latitude plants to exhibit higher aboveground growth persisted in each of the three locations (Fig. 3). The trend itself did not exhibit plasticity (Table 3) and was almost certainly not caused by variation in seed mass (Fig. 9). This is perhaps a surprising result, as it seems to suggest that lowerlatitude populations are best adapted at all latitudes; in other words, despite the genetic basis of clines in plant traits, we did not find evidence for local adaptation of growth rate. This seeming paradox has been reported for clines in some animal species as well (Lankford et al. 2001). Nonetheless, in some other transplant studies, reversals of latitudinal trends in performance consistent with local adaptation have been found (Chapin and Chapin 1981, Santamaría et al. 2003, Maron et al. 2004).

TABLE 4. Analysis of latitude and precipitation of the sampled populations as predictors of plant resistance to insects on Asclepias syriaca.

\begin{tabular}{|c|c|c|c|c|c|}
\hline Experiment and trait & $\begin{array}{c}\text { Sampling regime } \\
\text { (plants per population) }\end{array}$ & $\begin{array}{l}\text { Overall model, } \\
F \text { ratio }\end{array}$ & $R^{2}$ & $\begin{array}{l}\text { Precipitation } \\
\text { (coefficient) }\end{array}$ & $\begin{array}{l}\text { Latitude } \\
\text { (coefficient) }\end{array}$ \\
\hline \multicolumn{6}{|l|}{2009 New York common garden $(n=22)$} \\
\hline Aphids per stem (Myzocallis asclepiadis) & $\sim 7$ & $4.22 \%$ & 0.31 & $-0.18 *$ & $-0.048 *$ \\
\hline Monarch mass bioassay (Danaus plexippus) & $\sim 8$ & $5.01 *$ & 0.34 & $-0.004 *$ & $-0.009 \dagger$ \\
\hline \multicolumn{6}{|l|}{2010 North Carolina common garden $(n=11)$} \\
\hline Aphids per plant (Aphis nerii) $\$$ & $\sim 9$ & 2.63 & 0.37 & -0.010 & 0.069 \\
\hline Monarchs per plant (Danaus plexippus) $\ddagger$ & $\sim 9$ & 2.47 & 0.38 & $-0.002 \dagger$ & $-0.010 \dagger$ \\
\hline Small milkweed bugs per plant (Lygaeus kalmii) $\ddagger$ & $\sim 9$ & $6.35^{*}$ & 0.61 & 0.002 & $-0.039 *$ \\
\hline
\end{tabular}

Notes: The analyses used multiple regression on population means from plants in common gardens. Sample size $(n)$ is the number of populations sampled. All insect data were $\log (x+1)$ transformed. Values in boldface type are statistically significant. Coefficients are $r$ values.

$* P<0.05 ; * * P<0.01 ; * * * P<0.001 ; \dagger P<0.1$.

\pm For the three common insects, MANOVA results for precipitation were Wilks' lambda $=0.383, F_{3,6}=3.22, P<0.1$; for latitude, Wilks' lambda $=0.265, F_{3,6}=5.55, P<0.05$. 

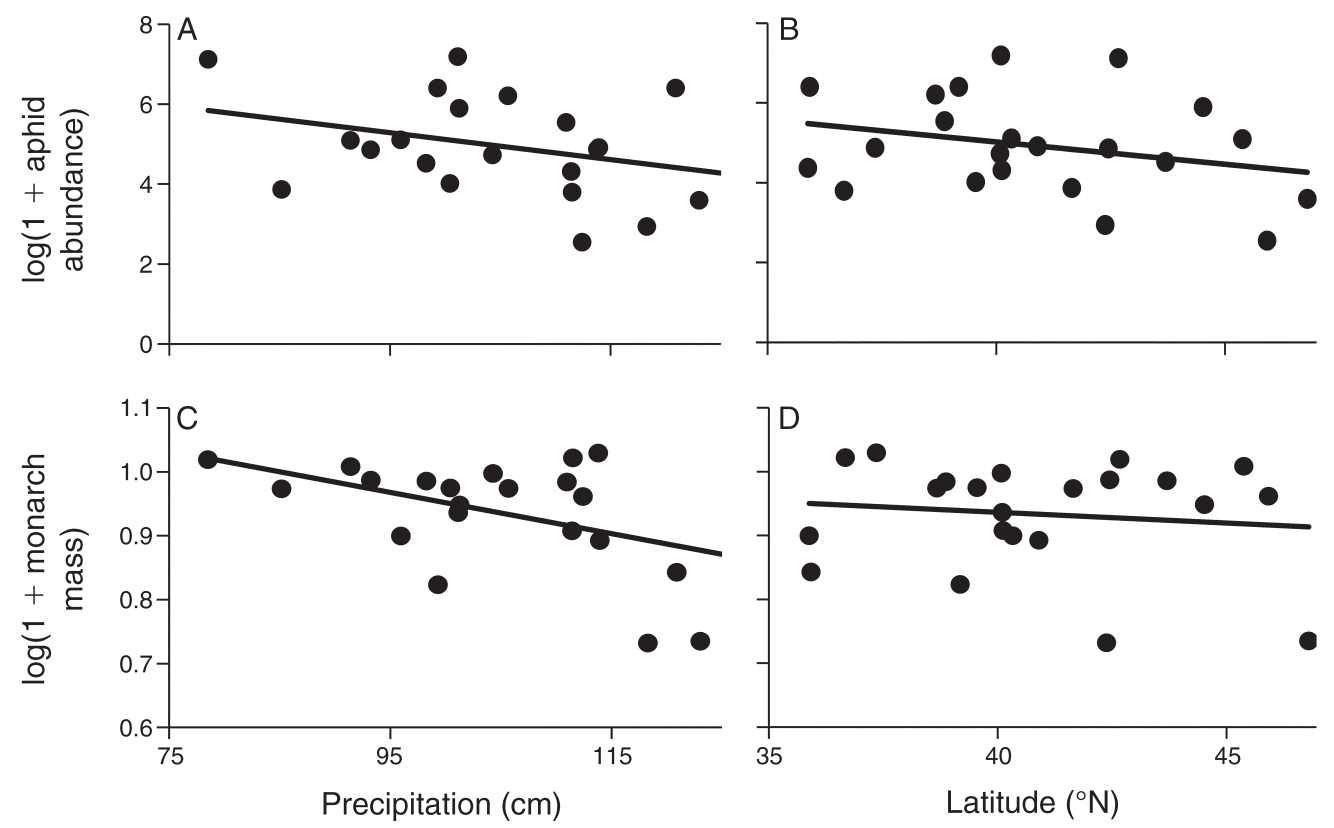

FIG. 8. (A, B) Aphid abundance and (C, D) monarch mass, an estimate of caterpillar performance from the New York common garden, were negatively correlated with both the precipitation and latitude of the collection sites $(n=22$ populations of $A$. syriaca; Table 4). These relationships are independent of plant size, as this was included as a covariate for aphids, and for the monarch bioassay, caterpillars were caged on the apical part of the plant. Shown are the log-transformed data from simple regressions.

The apparent paradox of low-latitude plants growing best in all environments can be resolved with the realization that allocation to aboveground and belowground growth must be considered in connection to longer-term fitness. The greater allocation to clonal (belowground) reproduction and root-to-shoot ratio we observed in higher-latitude populations (Fig. 5) is consistent with a reduced reliance on flowering and pollination there ( $A$. syriaca is largely self-incompatible [Kephart 1981]). Indeed, the northernmost populations of A. syriaca face a $60-70 \%$ shorter growing season than at the range center. In addition, allocation of relatively

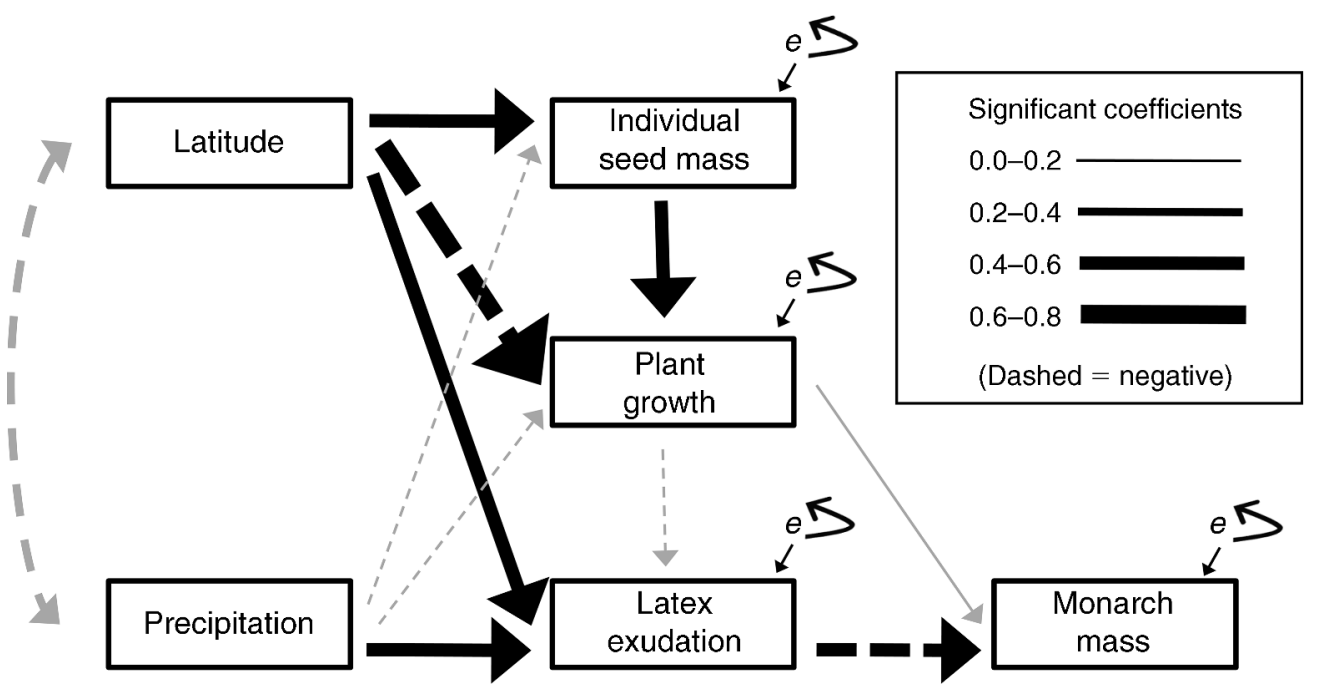

FIG. 9. Path analysis using populations means ( $n=22$ populations of $A$. syriaca) for effects of latitude and precipitation of the collection sites on plant traits and resistance to monarch caterpillars (Danaus plexippus) in a field bioassay in the New York common garden. The symbol $e$ is the remaining unexplained variation for measured traits. Solid and dashed black lines denote significant positive and negative path coefficients, respectively, with their thickness weighted by the strength of the coefficient. Gray arrows are similarly coded but are not associated with statistically significant path coefficients. 

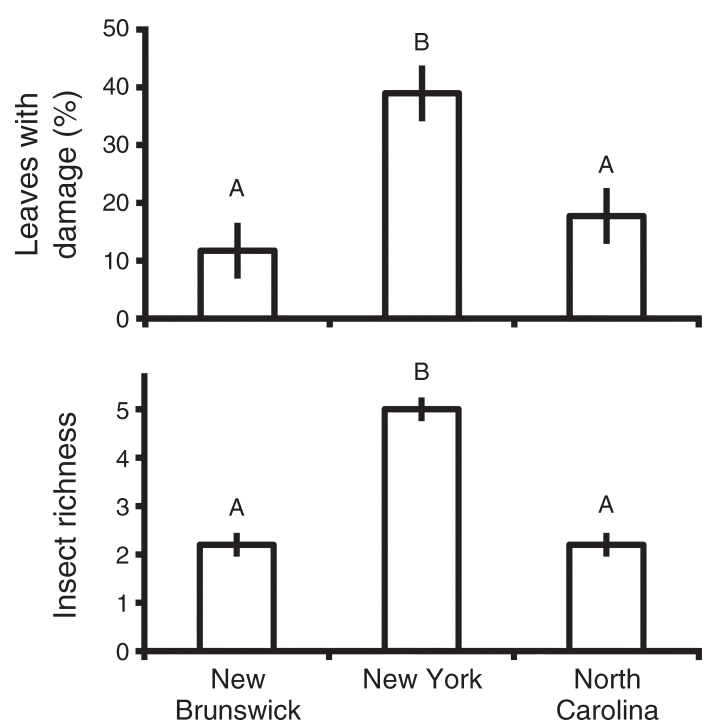

FIG. 10. Plant damage and insect richness on Asclepias syriaca at five naturally occurring sites at each location. New Brunswick and North Carolina are close to the northern and southern range edges, respectively. Data are least-squares means \pm SE across surveys conducted in both 2009 and 2010 . Different letters above bars represent significant $(P<0.05)$ differences using Tukey's HSD.

greater resources to underground tissues may help highlatitude plants rebound from winter stress and achieve early phenology in their limited growing season (Harris et al. 1983). Consistent with this, higher root-to-shoot ratios were genetically correlated with early phenology in the north $(n=22$ populations, $r=0.764, P<0.001)$. In other taxa, especially fish, there is strong evidence for geographical selection for allocation patterns that maximize over-winter survival (Conover and Present 1990, Billerbeck et al. 2000). Taken together, these considerations imply that belowground growth and clonal reproduction are a larger component of fitness at high latitudes, and the rapid aboveground growth expressed by low-latitude plants may be maladaptive at high latitudes. We suspect that differential clinal mortality or reproduction, consistent with local adaptation, would have been evident in a longer-term study of A. syriaca; however, we terminated our study after just two growing seasons in order to prevent the dispersal and integration of genes from the entire gradient into the study areas.

The other growth strategy traits we measured, in addition to aboveground biomass, also showed latitudinal clines, with some evidence for local adaptation. Early phenology correlated positively with growth at our northernmost common garden, but late phenology favored growth at our southernmost common garden (Table 3, Fig. 7). The consistency of earlier phenology in higher-latitude populations was demonstrated by Turesson (1930) over 80 years ago in his common environment studies of 31 European plant species. Although population variation in phenology appears to be adaptive, we did observe plasticity in the expression of this cline. (It was observed in New York and North Carolina, but not New Brunswick. Table 2; Appendix E.)

\section{Genetically based geographic clines in defense and herbivory}

Much has been written about latitudinal patterns in plant defense and herbivory, including some recent controversy about whether there is any general pattern (Levin 1976, Coley and Aide 1991, Lewinsohn 1991, Bolser and Hay 1996, Coley and Barone 1996, Schemske et al. 2009, Moles et al. 2011, Rasmann and Agrawal 2011). Given the long-held view that the growth and defense of plants is connected physiologically and evolutionarily (Coley et al. 1985, Herms and Mattson 1992), our examination of defenses and herbivory on plants from the 22 populations of $A$. syriaca was targeted at understanding overall strategies expressed along broad geographic gradients. Although natural herbivory in our study was lower on higher-latitude populations in the North Carolina common garden, this effect was driven primarily by plant size, and not defensive traits. In our New York common garden, however, we had better replicated assays of natural aphid attack and a bioassay of monarch caterpillar performance. Plant size was not a factor in either assay, and we found higher levels of resistance in higherlatitude plant populations, as well as higher resistance in populations with greater levels of annual precipitation.

For milkweeds, the most potent aspects of defense are latex and cardenolides. In the current study, resistance to monarch butterflies was driven by latex, while resistance to aphids was driven by trichomes and water content. The direct path between higher latitude, greater latex exudation, and reduced monarch performance (Fig. 9) convincingly shows the link between climate, plant defense, and impacts on herbivores. Nonetheless, for aphids, the path between climate, plant traits, and aphid abundance was less clear, and other unmeasured traits are implicated (Appendix F).

Milkweed populations in our experiment varied substantially in foliar cardenolides (Table 1), yet cardenolides did not show the predicted effect on resistance or clines along latitude or precipitation gradients (Table 2). In a study of natural populations, Malcolm (1995) found an east-west gradient in production of cardenolides by A. syriaca, but this relationship was relatively weak. A reanalysis of these data, splitting them into east-west and north-south transects, showed some evidence for a cline of increasing cardenolides at higher latitudes (Hunter et al. 1996). Our common garden assessment of cardenolides revealed a marginal correlation with latitude in 2008 (again, higher levels at higher latitudes), but no relationship in 2009. Nonetheless, given the genetically based cline of greater latex exudation at higher latitudes, and concentrated cardenolides in latex (Agrawal et al. 2008, Agrawal and 
Konno 2009), cardenolides may indirectly contribute to higher plant resistance at high latitudes.

Our results for patterns of defense and herbivory are opposite to the prediction that plants from lower latitudes will invest more in defense (Coley and Barone 1996, Pennings et al. 2001). This finding raises two important issues in the broader ecological context: whether we should expect similar results from comparisons between or within species, and whether we should expect within-species patterns that correlate with climate (or its proxy, latitude) or instead with population location with respect to the species' geographical range.

Historically, most arguments about the intensity of biotic interactions increasing at lower latitudes have been comparative (among species), suggesting that species residing at lower latitudes are more likely to possess particular defenses or have greater investment in defense compared to species from higher latitudes. Such comparative assessments have only recently been conducted in a phylogenetic framework, which is essential because the evolutionary history of radiations may not be independent of latitude (Bolser and Hay 1996). For the genus Asclepias, we have found that species from lower latitudes are better defended by toxic cardenolides compared to higher-latitude species (Rasmann and Agrawal 2011). Thus, despite some controversy (Moles et al. 2011), traits that are unequivocally defensive, such as latex (Lewinsohn 1991), alkaloids (Levin 1976), extrafloral nectaries (Pemberton 1998), and cardenolides (Rasmann and Agrawal 2011) show a pattern of increased defense in lower-latitude species. Because such species-level comparisons are made among reproductively isolated groups and typically use the mean latitude of a species' range, the inference made is about climate and macroevolutionary diversification.

Intraspecific tests of gradients in defense and herbivory focus on smaller-scale local adaptation in the face of gene flow and have taken two forms. First, patterns of damage have been assessed in natural populations. These analyses have had inconsistent results, including positive, negative, and no clines with latitude (Andrew and Hughes 2005, Adams and Zhang 2009, Pennings et al. 2009). The ecological and evolutionary importance of these patterns (or lack thereof) is unclear, however, because they reflect both the phenotypic expression of defense (genetic and environmental components) as well as effects of the abundance and preferences of local herbivores. Second, studies have measured damage in common gardens and reciprocal transplants, and some studies have supported the hypothesis of greater herbivory and defense at lower latitudes (Salgado and Pennings 2005, Pennings et al. 2009). However, in a meta-analysis of common garden experiments assessing plant allocation, there was no general trend in genetically based allocation to defense traits (or in insect damage) across latitude in 10 plant species (Colautti et al. 2009).
Several studies have shown significant genetically based latitudinal gradients of higher resistance at higher latitudes, consistent with our findings on common milkweed, but opposite to the prevailing view of among-species patterns. Early work by Bryant and colleagues demonstrated higher levels of defense in highlatitude boreal trees compared to lower-latitude trees (Bryant et al. 1989, 1994, Swihart et al. 1994). In a common garden study of Melaleuca quinquenervia, collections from higher latitudes had lower levels of insect damage, suggesting greater investment in defense traits (Franks et al. 2008, Colautti et al. 2009). In another common garden study spanning $8^{\circ}$ of latitude, N. E. Turley, D. M. Evans, and J. J. Tewksbury (unpublished manuscript), found higher levels of herbivory on lower-latitude populations compared to higherlatitude populations of black nightshade (Solanum americanum). Finally, in a common garden study of Pinus ponderosa, Gerson et al. (2009) reported that alkaloid production was correlated with mean temperatures (negatively) and precipitation (positively) of the collection sites. Thus, several studies, on both trees and herbaceous plants, demonstrate increasing defense investment at higher latitudes.

It remains unclear why gradients in defense are not consistent among studies and may even differ between intra- and interspecific comparisons. One potential explanation for a diversity of patterns in intraspecific analyses is that latitude or climatic variables per se may be less important in predicting herbivory or other interactions than a population's position relative to the species' range. Depending on how specialized the herbivores are, and thus whether alternative food plants are available, range-center populations may be subject to the greatest levels of attack (e.g., Garcia et al. 2000, Alexander et al. 2007). We similarly found that herbivore diversity and leaf damage for common milkweed was greatest towards the center (New York sites) compared to the northern and southern range edges. Nonetheless, patterns of defense allocation did not follow this distance from range-center pattern. We know little about gradients of damage within the central part of the range, which still covers $>6^{\circ}$ of latitude (Fig. 2). The high levels of defense in New Brunswick, despite the low levels of specialist attack there, suggests that protection from generalist herbivores (e.g., mollusks) may be particularly important at higher latitudes; while we observed heavy molluskan herbivory in one year of observations, we lack the long-term data to evaluate this notion.

\section{Growth-defense relationships in clinal evolution}

Ultimately the impact of herbivores on plant fitness will determine selection for defenses. We know little about the fitness impacts of milkweed herbivores along the latitudinal gradient. Nonetheless, slower-growing genotypes at higher latitudes are less likely to tolerate a given level of herbivory, as has been suggested and 
found in a variety of other contexts (Coley et al. 1985, Milchunas and Lauenroth 1993, Stowe 1998, Fine et al. 2004). Pennings and Silliman (2005) suggested further that the per capita impact of high- vs. low-latitude herbivores may differ. Such differential interaction strengths could decouple the relationship between plant resistance traits and the local fitness impacts of herbivores.

The evolution of slow growth in response to climate or resource availability is predicted to be associated with higher levels of investment in defense, and this pattern appears to be borne out in interspecific comparisons (Janzen 1974, Coley et al. 1985, Arendt 1997, Endara and Coley 2011). Although our overall qualitative pattern was consistent with this hypothesis (i.e., northern populations were slower growing and better defended), we did not find evidence for a quantitative relationship between growth and latex production in any of three common gardens (or growth and monarch butterfly performance in the New York common garden). This pattern suggests that clines in both growth and defense evolved along the latitudinal gradient, but were not driven by a physiological or genetic link between the two. One possible scenario is that slow growth evolves in response to climate, making plants less tolerant of herbivory, and thereby favoring higher levels of resistance (Coley et al. 1985). There are two important outcomes of this scenario. First, growth and resistance traits would not necessarily be directly correlated. Second, the absolute amount of herbivory at different geographical locations may be less indicative of the investment in defense than the impact of that herbivory on plant performance.

More generally, observations of geographic clines in growth have not been well linked to defense in plants or animals (Arendt 1997, Colautti et al. 2009). An exception is work on the Atlantic silverside fish (Menidia menidia) where northern populations are selected for rapid growth, to promote overwinter survival, and appear to be superior in all aspects of growth compared to more southern populations (Conover and Present 1990, Billerbeck et al. 2000). Nonetheless, more recent work has shown that both genetically based faster growth rate and phenotypic manipulations of faster growth rate are associated with increased risk of predation compared to slower-growing fish (Lankford et al. 2001, Munch and Conover 2003). In summary, we advocate for combined research on growth and defense traits from organisms across geographical gradients. Without the ability to examine the direct correlations between climatic variables (or a proxy, such as latitude) and genetically based differences in traits, it will be difficult to unravel the drivers of clinal evolution.

\section{Latitudinal clines, climate change, and species invasions}

The existence of contemporary genetically based latitudinal clines in traits is suggestive of strong climatic selection and sufficiently limited gene flow to allow for local adaptation (Endler 1977). Current climate change is imposing natural selection on a broad array of organisms (Parmesan 2006). Thus, for species with broad distributions and existing latitudinal clines, adaptation to climate change seems plausible. Nonetheless, the extent of adaptation we can expect has been debated, in part because of genetic constraints and barriers to dispersal and gene flow (Davis et al. 2005, Skelly et al. 2007, Aitken et al. 2008, Colautti et al. 2010). For example, classic work on the partridge pea (Chamaecrista fasciculata) indicated that although plant populations were locally adapted, genetic correlations may constrain future adaptation to climate change (Etterson and Shaw 2001, Etterson 2004). In other cases, there appears to be concordance between latitudinal patterns and responses to climate change. In birds, for example, there are within-species latitudinal patterns in body size (i.e., Bergman's rule; larger sizes at higher latitudes) (Ashton 2002) and this pattern has been reflected in analyses of phenotypic changes associated with climate (Van Buskirk et al. 2010).

The rapid evolution of traits of invasive species in response to climatic gradients provides a window into the possibility of adaptation to climate change (Lee 2002). For example, Huey et al.'s landmark study (2000) of Drosophila subobscura's invasion of North America showed that a latitudinal cline in wing size, present in native populations, took only $1-2$ decades to evolve in the introduced range. These flies have continued to evolve in response to climate change. Indeed, among 22 populations on three continents that have experienced warming over the past two decades, 21 showed a pattern of evolution towards lower-latitude (i.e., warmer climate) genotypes (Balanya et al. 2006). For plants, which are often more sessile than animals, parallel clines in morphological and life-history traits among native and invasive populations have also led to the conclusion of rapid evolution to climatic conditions in several systems (Maron et al. 2004, Etterson et al. 2008, Montague et al. 2008, Alexander et al. 2009). While A. syrica was introduced to Europe nearly a century ago, and has spread over at least $6^{\circ}$ of latitude, little is known about adaptation to climate (or herbivores) in that nonnative range. Finally, although much has been said about characteristics of species or ecological conditions allowing rapid adaptation to changing conditions, we currently have very few tests of these ideas for species facing climate change in the wild (Davis et al. 2005, Skelly et al. 2007, Aitken et al. 2008, Van Buskirk et al. 2010).

Adaptation to climatic gradients and the success of invasive species are not necessarily independent (RouraPascual et al. 2004). For example, a prominent hypothesis for the success of invasive species, the evolution of increased competitive ability (EICA), suggests that rapid evolution of invasive species, in the absence of their enemies from the native range, will lead to greater competitive ability (Blossey and Nötzold 
1995, Bossdorf et al. 2005). Nonetheless, most tests of this hypothesis have not accounted for the fact that invasive species typically proliferate at different latitudes than they inhabit in their native ranges, and may therefore be pre-adapted to some new environments (Colautti et al. 2009). In addition, under climate change, shifts in maximum and minimum temperatures (as opposed to changes in mean temperature), may give invasive species a phenological advantage, as has been suggested for invasive marine ascidians (Stachowicz et al. 2002). Finally, for native but weedy $A$. syriaca, decreasing seed size in southern populations may have contributed to its rapid range expansion southward, given that small milkweed seeds disperse farther than larger seeds (Morse and Schmitt 1985, Wyatt et al. 1993, Wyatt 1996). The continued study of adaptation to climatic gradients, in both native and nonnative species, thus holds promise for understanding evolutionary change in response to future environmental challenges.

\section{Concluding Speculation}

Given the complexity of biogeographic clines in species traits and interactions, a combined approach of studying natural populations and common gardens is essential for deciphering adaptation. For common milkweed, we found strong evidence for within-population heritable variation in growth and defense. Population-level adaptation along latitudinal and precipitation gradients appears to have resulted in the differentiation of several of these traits, and independently acts on seed mass, plant growth, and latex production. Although we find that a strong path between biogeographic clines and genetically based resistance to insects exists via latex production, we have not found a concordant gradient in herbivory that could have driven this pattern. This intriguing mismatch suggests that defenses against herbivory may be evolving as a byproduct of, or as constrained by, adaptation to climate. A key missing component of this story is our understanding of the per capita impact of herbivores on plants across the gradient; we speculate that lower tolerance of highlatitude populations may have favored higher levels of resistance. Thus, although there has clearly been adaptive evolution in response to climatic variation in natural populations, and plant defenses may also be affected by climate, A. syriaca appears to have evolved a cline in defense independent of the direct relationship between defense and plant growth or insect herbivore attack rates.

\section{ACKNOWLEDGMENTS}

For collecting seeds, we are grateful to the following people (listed by population in latitudinal order from north to south, except for Fredericton, New Brunswick, East Lansing, MI and Ithaca, New York, which were collected by the authors): Gilles Houle, Naomi Cappuccino, Allison Brody, Becky Irwin, Lynn Adler, Helen Michaels, Casey Delphia, Art Zangerl, Pat Dubin and Ed Wurtz, Josh Auld, Pete Van Zandt, Don Cipollini, T'ai Roulston, John Parker, Susan Gallaher, John Styrsky, William Cook, Marc Johnson, and Greg Crutsinger. We are grateful to
Robert Wyatt, who looked extensively for populations of Asclepias syriaca in South Carolina and Georgia.

We thank Robin Bingham, Daisy Johnson, Alexis Erwin, and Majorie Weber for help with field and lab work, and especially Marc Johnson for facilitating the North Carolina common garden. Thanks to Art Logan, Ed Stinson, and the New Brunswick Department of Natural Resources for extensive help with the Fredericton common garden. Sergio Rasmann and Rayko Halitschke provided critical guidance with chemical analyses, Mônica Kersch-Becker helped with statistical advice, Kurt Reiger (High Caliper Growing) donated the tree bags, and Rob Colautti, John Maron, Jennifer Thaler, Liz Wason, and anonymous reviewers provided helpful comments and discussion. This research was supported by NSF-DEB 0447550 and 0950231 to A. A. Agrawal and REU supplements that supported E. C. Woods, a Natural Sciences and Engineering Research Council (Canada) Discovery Grant to S. B. Heard, and an NSF graduate research fellowship to N. E. Turley.

\section{Literature Cited}

Adams, J. M., and Y. J. Zhang. 2009. Is there more insect folivory in warmer temperate climates? A latitudinal comparison of insect folivory in eastern North America. Journal of Ecology 97:933-940.

Agrawal, A. A. 2004. Resistance and susceptibility of milkweed: competition, root herbivory, and plant genetic variation. Ecology 85:2118-2133.

Agrawal, A. A. 2005. Natural selection on common milkweed (Asclepias syriaca) by a community of specialized insect herbivores. Evolutionary Ecology Research 7:651-667.

Agrawal, A. A. 2011. Current trends in the evolutionary ecology of plant defence. Functional Ecology 25:420-432.

Agrawal, A. A., J. K. Conner, and S. Rasmann. 2010. Tradeoffs and adaptive negative correlations in evolutionary ecology. Pages 243-268 in M. Bell, W. Eanes, D. Futuyma, and J. Levinton, editors. Evolution after Darwin: the first 150 years. Sinauer Associates, Sunderland, Massachusetts, USA.

Agrawal, A. A., and K. Konno. 2009. Latex: a model for understanding mechanisms, ecology, and evolution of plant defense against herbivory. Annual Review of Ecology, Evolution, and Systematics 40:311-331.

Agrawal, A. A., M. J. Lajeunesse, and M. Fishbein. 2008. Evolution of latex and its constituent defensive chemistry in milkweeds (Asclepias): a test of phylogenetic escalation. Entomologia Experimentalis et Applicata 128:126-138.

Agrawal, A. A., and S. B. Malcolm. 2002. Once upon a milkweed. Natural History 111(7):48-53.

Agrawal, A. A., and P. A. Van Zandt. 2003. Ecological play in the coevolutionary theatre: genetic and environmental determinants of attack by a specialist weevil on milkweed. Journal of Ecology 91:1049-1059.

Aitken, S. N., S. Yeaman, J. A. Holliday, T. L. Wang, and S. Curtis-McLane. 2008. Adaptation, migration or extirpation: climate change outcomes for tree populations. Evolutionary Applications 1:95-111.

Alexander, H. M., S. Price, R. Houser, D. Finch, and M. Tourtellot. 2007. Is there reduction in disease and predispersal seed predation at the border of a host plant's range? Field and herbarium studies of Carex blanda. Journal of Ecology 95:446-457.

Alexander, J. M., P. J. Edwards, M. Poll, C. G. Parks, and H. Dietz. 2009. Establishment of parallel altitudinal clines in traits of native and introduced forbs. Ecology 90:612-622.

Andrew, N. R., and L. Hughes. 2005. Herbivore damage along a latitudinal gradient: relative impacts of different feeding guilds. Oikos 108:176-182.

Antoniazza, S., R. Burri, L. Fumagalli, J. Goudet, and A. Roulin. 2010. Local adaptation maintains clinal variation in melanin-based coloration of european barn owls (Tyto alba). Evolution 64:1944-1954. 
Arendt, J. D. 1997. Adaptive intrinsic growth rates: an integration across taxa. Quarterly Review of Biology 72:149-177.

Arft, A. M., et al. 1999. Responses of tundra plants to experimental warming: meta-analysis of the international tundra experiment. Ecological Monographs 69:491-511.

Ashton, K. G. 2002. Patterns of within-species body size variation of birds: strong evidence for Bergmann's rule. Global Ecology and Biogeography 11:505-523.

Balanya, J., J. M. Oller, R. B. Huey, G. W. Gilchrist, and L. Serra. 2006. Global genetic change tracks global climate warming in Drosophila subobscura. Science 313:1773-1775.

Billerbeck, J. M., E. T. Schultz, and D. O. Conover. 2000. Adaptive variation in energy acquisition and allocation among latitudinal populations of the Atlantic silverside. Oecologia 122:210-219.

Bingham, R. A., and A. A. Agrawal. 2010. Ecological genetics of herbivore-specific induced defenses in common milkweed. Journal of Ecology 98:1014-1022.

Blossey, B., and R. Nötzold. 1995. Evolution of increased competitive ability in invasive nonindigenous plants: a hypothesis. Journal of Ecology 83:887-889.

Bolser, R. C., and M. E. Hay. 1996. Are tropical plants better defended? Palatability and defenses of temperate vs. tropical seaweeds. Ecology 77:2269-2286.

Bossdorf, O., H. Auge, L. Lafuma, W. E. Rogers, E. Siemann, and D. Prati. 2005. Phenotypic and genetic differentiation between native and introduced plant populations. Oecologia 144:1-11.

Bryant, J. P., R. K. Swihart, P. B. Reichardt, and L. Newton. 1994. Biogeography of woody plant chemical defense against snowshoe hare browsing: comparison of Alaska and eastern North America. Oikos 70:385-395.

Bryant, J. P., J. Tahvanainen, M. Sulkinoja, R. Julkunentiitto, P. Reichardt, and T. Green. 1989. Biogeographic evidence for the evolution of chemical defense by boreal birch and willow against mammalian browsing. American Naturalist 134:2034.

Chapin, F. S., K. Autumn, and F. Pugnaire. 1993. Evolution of suites of traits in response to environmental stress. American Naturalist 142:S78-S92.

Chapin, F. S., and M. C. Chapin. 1981. Ecotypic differentiation of growth-processes in Carex aquatilis along latitudinal and local gradients. Ecology 62:1000-1009.

Clausen, J., D. Keck, and W. Hiesey. 1948. Experimental studies on the nature of species III. Carnegie Institute of Washington Publication 581. Carnegie Institute of Washington, Washington, D.C., USA.

Colautti, R. I., C. G. Eckert, and S. C. H. Barrett. 2010. Evolutionary constraints on adaptive evolution during range expansion in an invasive plant. Proceedings of the Royal Society B 277:1799-1806.

Colautti, R. I., J. L. Maron, and S. C. H. Barrett. 2009. Common garden comparisons of native and introduced plant populations: latitudinal clines can obscure evolutionary inferences. Evolutionary Applications 2:187-199.

Coley, P. D., and T. M. Aide. 1991. Comparison of herbivory and plant defenses in temperate and tropical broad-leaved forests. In P. W. Price, T. M. Lewinsohn, G. W. Fernandes, and W. W. Benson, editors. Plant-animal interactions: evolutionary ecology in tropical and temperate regions. John Wiley and Sons, New York, New York, USA.

Coley, P. D., and J. A. Barone. 1996. Herbivory and plant defenses in tropical forests. Annual Review of Ecology and Systematics 27:305-335.

Coley, P. D., J. P. Bryant, and F. S. Chapin. 1985. Resource availability and plant antiherbivore defense. Science 230:895899.

Conover, D. O., and T. M. C. Present. 1990. Countergradient variation in growth-rate. Compensation for length of the growing-season among Atlantic silversides from different latitudes. Oecologia 83:316-324.
Davis, M. B., R. G. Shaw, and J. R. Etterson. 2005. Evolutionary responses to changing climate. Ecology 86:1704-1714.

Dobzhansky, T. 1950. Evolution in the tropics. American Scientist 38:209-221.

Endara, M. J., and P. D. Coley. 2011. The resource availability hypothesis revisited: a meta-analysis. Functional Ecology 25:389-398.

Endler, J. A. 1977. Geographic variation, speciation, and clines. Princeton University Press, Princeton, New Jersey, USA.

Etterson, J. R. 2004. Evolutionary potential of Chamaecrista fasciculata in relation to climate change. 1. Clinal patterns of selection along an environmental gradient in the Great Plains. Evolution 58:1446-1458.

Etterson, J. R., D. E. Delf, T. P. Craig, Y. Ando, and T. Ohgushi. 2008. Parallel patterns of clinal variation in Solidago altissima in its native range in central USA and its invasive range in Japan. Botany-Botanique 86:91-97.

Etterson, J. R., and R. G. Shaw. 2001. Constraint to adaptive evolution in response to global warming. Science 294:151154.

Fine, P. V. A., I. Mesones, and P. D. Coley. 2004. Herbivores promote habitat specialization by trees in Amazonian forests. Science 305:663-665.

Franks, S. J., P. D. Pratt, F. A. Dray, and E. L. Simms. 2008. No evolution of increased competitive ability or decreased allocation to defense in Melaleuca quinquenervia since release from natural enemies. Biological Invasions 10:455-466.

Garcia, D., R. Zamora, J. M. Gomez, P. Jordano, and J. A. Hodar. 2000. Geographical variation in seed production, predation and abortion in Juniperus communis throughout its range in Europe. Journal of Ecology 88:436-446.

Gaston, K. J. 2009. Geographic range limits: achieving synthesis. Proceedings of the Royal Society B 276:1395-1406.

Gerson, E. A., R. G. Kelsey, and J. B. St Clair. 2009. Genetic variation of piperidine alkaloids in Pinus ponderosa: a common garden study. Annals of Botany 103:447-457.

Gold, J. J., and J. S. Shore. 1995. Multiple paternity in Asclepias syriaca using a paired-fruit analysis. Canadian Journal of Botany 73:1212-1216.

Hall, D., V. Luquez, V. M. Garcia, K. R. St Onge, S. Jansson, and P. K. Ingvarsson. 2007. Adaptive population differentiation in phenology across a latitudinal gradient in European Aspen (Populus tremula, L.): a comparison of neutral markers, candidate genes and phenotypic traits. Evolution 61:2849-2860.

Harper, J. L. 1977. Population biology of plants. Academic Press, London, UK.

Harris, W., I. Rhodes, and S. S. Mee. 1983. Observations on environmental and genotypic influences on the overwintering of white clover. Journal of Applied Ecology 20:609-624.

Helferich, G. 2004. Humboldt's cosmos: Alexander von Humboldt and the Latin American journey that changed the world. Gotham Books, New York, New York, USA.

Herms, D. A., and W. J. Mattson. 1992. The dilemma of plants: to grow or defend. Quarterly Review of Biology 67:283-335.

Huey, R. B., G. W. Gilchrist, M. L. Carlson, D. Berrigan, and L. Serra. 2000. Rapid evolution of a geographic cline in size in an introduced fly. Science 287:308-309.

Hunter, M. D., S. B. Malcolm, and S. E. Hartley. 1996. Population-level variation in plant secondary chemistry, and the population biology of herbivores. Chemoecology 7:4556.

Janzen, D. H. 1974. Tropical blackwater rivers, animals, and mast fruiting by the Dipterocarpaceae. Biotropica 6:69-103.

Kephart, S. R. 1981. Breeding systems in Asclepias incarnata L., Asclepias syriaca L., and Asclepias verticillata L. American Journal of Botany 68:226-232.

Knight, A. P., and R. G. Walter. 2001. A guide to plant poisoning of animals in North America. Teton New Media, Jackson, Wyoming, USA. 
Kolbe, J. J., R. E. Glor, L. R. G. Schettino, A. C. Lara, A. Larson, and J. B. Losos. 2004. Genetic variation increases during biological invasion by a Cuban lizard. Nature 431:177-181.

Lambers, H., F. S. Chapin, and T. L. Pons. 1998. Plant physiological ecology. Springer, New York, New York, USA.

Lande, R., and S. J. Arnold. 1983. The measurement of selection on correlated characters. Evolution 37:1210-1226.

Lankford, T. E., J. M. Billerbeck, and D. O. Conover. 2001. Evolution of intrinsic growth and energy acquisition rates. II. Trade-offs with vulnerability to predation in Menidia menidia. Evolution 55:1873-1881.

Lee, C. E. 2002. Evolutionary genetics of invasive species. Trends in Ecology and Evolution 17:386-391.

Levin, D. A. 1976. Alkaloid-bearing plants - ecogeographic perspective. American Naturalist 110:261-284.

Lewinsohn, T. M. 1991. The geographical distribution of plant latex. Chemoecology 2:64-68.

Li, B., J. I. Suzuki, and T. Hara. 1998. Latitudinal variation in plant size and relative growth rate in Arabidopsis thaliana. Oecologia 115:293-301.

Malcolm, S. B. 1991. Cardenolide-mediated interactions between plants and herbivores. Pages 251-296 in G. A. Rosenthal and M. R. Berenbaum, editors. Herbivores: their interactions with secondary plant metabolites. Volume I: The chemical participants. Second edition. Academic Press, San Diego, California, USA.

Malcolm, S. B. 1995. Milkweeds, monarch butterflies and the ecological significance of cardenolides. Chemoecology 5/6:101-117.

Maron, J. L., M. Vila, R. Bommarco, S. Elmendorf, and P. Beardsley. 2004. Rapid evolution of an invasive plant. Ecological Monographs 74:261-280.

Mayr, E. 1956. Geographical character gradients and climatic adaption. Evolution 10:105-108.

Milchunas, D. G., and W. K. Lauenroth. 1993. Quantitative effects of grazing on vegetation and soils over a global range of environments. Ecological Monographs 63:327-366.

Moles, A. T., D. D. Ackerly, J. C. Tweddle, J. B. Dickie, R. Smith, M. R. Leishman, M. M. Mayfield, A. Pitman, J. T. Wood, and M. Westoby. 2007. Global patterns in seed size. Global Ecology and Biogeography 16:109-116.

Moles, A. T., S. P. Bonser, A. G. B. Poore, I. R. Wallis, and W. J. Foley. 2011. Assessing the evidence for latitudinal gradients in plant defence and herbivory. Functional Ecology 25:380-388.

Montague, J. L., S. C. H. Barrett, and C. G. Eckert. 2008. Reestablishment of clinal variation in flowering time among introduced populations of purple loosestrife (Lythrum salicaria, Lythraceae). Journal of Evolutionary Biology 21:234-245.

Mooney, K. A., and A. A. Agrawal. 2008. Plant genotype shapes ant-aphid interactions: implications for community structure and indirect plant defense. American Naturalist 171:E195-E205.

Mooney, K. A., R. Halitschke, A. Kessler, and A. A. Agrawal. 2010. Evolutionary trade-offs in plants mediate the strength of trophic cascades. Science 327:1642-1644.

Morse, D. H., and J. Schmitt. 1985. Propagule size, dispersal ability, and seedling performance in Asclepias syriaca. Oecologia 67:372-379.

Munch, S. B., and D. O. Conover. 2003. Rapid growth results in increased susceptibility to predation in Menidia menidia. Evolution 57:2119-2127.

Parmesan, C. 2006. Ecological and evolutionary responses to recent climate change. Annual Review of Ecology, Evolution, and Systematics 37:637-669.

Pemberton, R. W. 1998. The occurrence and abundance of plants with extrafloral nectaries, the basis for antiherbivore defensive mutualisms, along a latitudinal gradient in east Asia. Journal of Biogeography 25:661-668.
Pennings, S. C., C. K. Ho, C. S. Salgado, K. Wieski, N. Dave, A. E. Kunza, and E. L. Wason. 2009. Latitudinal variation in herbivore pressure in Atlantic Coast salt marshes. Ecology 90:183-195.

Pennings, S. C., and B. R. Silliman. 2005. Linking biogeography and community ecology: latitudinal variation in plantherbivore interaction strength. Ecology 86:2310-2319.

Pennings, S. C., E. L. Siska, and M. D. Bertness. 2001. Latitudinal differences in plant palatability in Atlantic coast salt marshes. Ecology 82:1344-1359.

Pilon, J., L. Santamaría, M. Hootsmans, and W. van Vierssen. 2003. Latitudinal variation in life-cycle characteristics of Potamogeton pectinatus L.: vegetative growth and asexual reproduction. Plant Ecology 165:247-262.

Rasmann, S., and A. A. Agrawal. 2011. Latitudinal patterns in plant defense: evolution of cardenolides, their toxicity and induction following herbivory. Ecology Letters 14:476-483.

Rasmann, S., M. D. Johnson, and A. A. Agrawal. 2009. Induced responses to herbivory and jasmonate in three milkweed species. Journal of Chemical Ecology 35:13261334.

Roura-Pascual, N., A. V. Suarez, C. Gomez, P. Pons, Y. Touyama, A. L. Wild, and A. T. Peterson. 2004. Geographical potential of Argentine ants (Linepithema humile Mayr) in the face of global climate change. Proceedings of the Royal Society B 271:2527-2534.

Salgado, C. S., and S. C. Pennings. 2005. Latitudinal variation in palatability of salt-marsh plants: Are differences constitutive? Ecology 86:1571-1579.

Santamaría, L., J. Figuerola, J. J. Pilon, M. Mjelde, A. J. Green, T. De Boer, R. A. King, and R. J. Gornall. 2003. Plant performance across latitude: the role of plasticity and local adaptation in an aquatic plant. Ecology 84:2454-2461.

Schemske, D. W., G. G. Mittelbach, H. V. Cornell, J. M. Sobel, and K. Roy. 2009. Is there a latitudinal gradient in the importance of biotic interactions? Annual Review of Ecology, Evolution, and Systematics 40:245-269.

Simms, E. L. 1992. Costs of plant resistance to herbivores. Pages 392-425 in R. S. Fritz and E. L. Simms, editors. Plant resistance to herbivores and pathogens. Ecology, evolution, and genetics. University of Chicago Press, Chicago, Illinois, USA.

Siska, E. L., S. C. Pennings, T. L. Buck, and M. D. Hanisak. 2002. Latitudinal variation in palatability of salt-marsh plants: Which traits are responsible? Ecology 83:3369-3381.

Skelly, D. K., L. N. Joseph, H. P. Possingham, L. K. Freidenburg, T. J. Farrugia, M. T. Kinnison, and A. P. Hendry. 2007. Evolutionary responses to climate change. Conservation Biology 21:1353-1355.

Smith, R. A., K. A. Mooney, and A. A. Agrawal. 2008. Coexistence of three specialist aphids on common milkweed, Asclepias syriaca. Ecology 89:2187-2196.

Spicer, R. A., and J. L. Chapman. 1990. Climate change and the evolution of high-latitude terrestrial vegetation and floras. Trends in Ecology and Evolution 5:279-284.

Stachowicz, J. J., J. R. Terwin, R. B. Whitlatch, and R. W. Osman. 2002. Linking climate change and biological invasions: Ocean warming facilitates nonindigenous species invasions. Proceedings of the National Academy of Sciences USA 99:15497-15500.

Stillwell, R. C. 2010. Are latitudinal clines in body size adaptive? Oikos 119:1387-1390.

Stillwell, R. C., G. E. Morse, and C. W. Fox. 2007. Geographic variation in body size and sexual size dimorphism of a seedfeeding beetle. American Naturalist 170:358-369.

Stowe, K. A. 1998. Experimental evolution of resistance in Brassica rapa: correlated response of tolerance in lines selected for glucosinolate content. Evolution 52:703-712.

Swihart, R. K., J. P. Bryant, and L. Newton. 1994. Latitudinal patterns in consumption of woody giants by snowshoe hares in the eastern United States. Oikos 70:427-434.

Systat. 2007. Systat version 12. Systat, Chicago, Illinois, USA. 
Turesson, G. 1930. The selective effect of climate upon the plant species. Hereditas 14:99-152.

Van Buskirk, J., R. S. Mulvihill, and R. C. Leberman. 2010. Declining body sizes in North American birds associated with climate change. Oikos 119:1047-1055.

Van Zandt, P. A., and A. A. Agrawal. 2004. Specificity of induced plant responses to specialist herbivores of the common milkweed, Asclepias syriaca. Oikos 104:401-409.

Winn, A. A., and K. L. Gross. 1993. Latitudinal variation in seed weight and flower number in Prunella vulgaris. Oecologia 93:55-62.

Woodson, R. E. 1954. The North American species of Asclepias L. Annals of the Missouri Botanical Garden 41:1-211.
Wyatt, R. 1996. More on the southward spread of common milkweed, Asclepias syriaca L. Bulletin of the Torrey Botanical Club 123:68-69.

Wyatt, R., A. Stoneburner, S. B. Broyles, and J. R. Allison. 1993. Range extension southward in common milkweed, Asclepias syriaca L. Bulletin of the Torrey Botanical Club 120:177-179.

Zalucki, M. P., and S. B. Malcolm. 1999. Plant latex and firstinstar monarch larval growth and survival on three North American milkweed species. Journal of Chemical Ecology 25:1827-1842.

\section{Supplemental Material}

\section{Appendix A}

Population collections of Asclepias syriaca used in this study and climatic data (Ecological Archives M082-005-A1).

\section{Appendix B}

A table of the correlations between latitude and four climatic variables (Ecological Archives M082-005-A2).

\section{Appendix C}

A table of the impacts of herbivory on phenotypic measures of common milkweed in the New York common garden (2008) (Ecological Archives M082-005-A3).

\section{Appendix D}

A figure showing the correlation between latitude and seed mass (Ecological Archives M082-005-A4).

\section{Appendix E}

A figure showing the correlation between latitude of the collection sites and early-season height in the New Brunswick and North Carolina common gardens (Ecological Archives M082-005-A5).

\section{Appendix F}

Path analysis for effects of latitude and precipitation of the collection sites on plant traits and abundance of aphids (Myzocallis asclepiadis) (Ecological Archives M082-005-A6).

\section{Data Availability}

Data associated with this paper have been deposited in Dryad: http://dx.doi.org/10.5061/dryad.gd856 